\title{
Transnacionalidad familiar: Estructuras familiares y trayectorias de reagrupación de los inmigrantes en España
}

\author{
LUIS CAMARERO \\ Sociología I. UNED \\ lcamarero@poli.uned.es
}

Recibido: 09.07.2009

Aceptado: 24.02 .2010

La movilidad migratoria constituye uno de los pilares centrales del funcionamiento del orden económico globalizado. Dicho de otra forma, el desarrollo de las economías globales se basa en la intensificación de la movilidad migratoria, intensificación que se corresponde con la reestructuración de los modelos migratorios. Pugliese (1993) que ha descrito el cambio en los modelos migratorios, en el contexto de la expansión de las actividades económicas más flexibles e irregulares que caracterizan lo que ha venido llamándose etapa postfordista, ha destacado la creciente feminización de las corrientes migratorias y el crecimiento de las poblaciones en situación irregular como dos de las características del modelo migratorio actual. En este artículo se observará en qué medida los nuevos modelos migratorios de la etapa postfordista se relacionan con profundos cambios en la propia organización familiar.

La reciente publicación de los datos de la Encuesta Nacional de Inmigración (ENI) hace posible por primera vez realizar un estudio amplio sobre las características y proceso de asentamiento de la población de origen extranjero en España, estudio que permite adentrarse en las formas de convivencia y desarrollo familiar. A partir de esta base de datos, el texto hará un recorrido de la inmigración en el contexto de las formas familiares para mostrar la importancia, así como la emergencia, de la familia transnacional en España. La tesis central del texto señala que la movilidad creciente que caracteriza a las sociedades contemporáneas incide en una reestructuración de las relaciones familiares.

Introduciremos y examinaremos, en primer lugar, la noción de núcleo transnacional. Es decir observaremos en qué medida los núcleos familiares - entendidos como el conjunto formado por el cónyuge, si lo hubiera, y los hijos pequeños, si los hubiera - residen juntos o dicho conjunto se encuentra disperso 
entre distintos países. Estableceremos así un índice de transnacionalidad que nos permitirá comprender en qué medida las migraciones transnacionales se encuadran dentro de estrategias familiares, estrategias que dirigen a algunos de sus miembros a la emigración. Dentro de esta lógica familiar de las migraciones transnacionales observaremos la relación que se establece en el lugar de destino entre los hogares de residencia y las estructuras familiares. En segundo lugar, el análisis se ocupará de la reagrupación familiar. Si bien la reagrupación es una fase transitoria en el proceso migratorio de orden familiar los ritmos en que esta se establece permiten especificar las formas familiares transnacionales.

\section{LA FAMILIA TRANSNACIONAL}

Los estudios postcoloniales, los debates sobre la transnacionalidad y los estudios de género han ido introduciendo nuevas reflexiones acerca del sentido social de los fenómenos migratorios y sobre las transformaciones en las estructuras sociales, tanto en destino como en origen, que implican las migraciones. Los estudios postocoloniales han señalado la emergencia de identidades híbridas que diluyen progresivamente la separación entre las categorías de nacional y extranjero. Precisamente esta es una de las cuestiones que inspiran un de los primeros textos que se centran en la noción de transnacionalidad, Nations Unbound (Basch, L. y Glick y Szanton-Blanc: 1994), para quienes las relaciones entre identidades nacionales y la superación de las mismas permiten diferenciar a los inmigrantes de lo que ellos denominan «transmigrantes». Desde los estudios de género se ha insertado la interpretación de los proyectos migratorios dentro de las estructuras familiares, mostrando la dependencia familiar de dichos proyectos y se ha destacado la reformulación de las estructuras familiares que implica el proceso migratorio ${ }^{1}$. A estos enfoques se suma la tesis de la transnacionalidad que muestra las relaciones recíprocas entre origen y destino superando la interpretación mecanicista del simple intercambio poblacional motivado por el ajuste de mercados laborales globales. Así, progresivamente se han ido abandonando las explicaciones homeostáticas sobre diferenciales salariales, de renta y de condiciones de vida con las que se simplificaba el hecho migratorio a la vez que se ocultaba la fuerza transformadora que suponen las corrientes migratorias. La preocupación por la adaptación de los inmigrantes a las sociedades receptoras es ahora repensada por la continua interrelación de los emigrantes con sus lugares de origen. (Portes, Guarnizo y Haller: 2002).

Desde la consideración de la emigración como dinámica social ha emergido la familia transnacional como concepto clave. (Parreñas: 2001). La familia

${ }^{1} \mathrm{Al}$ respecto resulta de interés el monográfico que dedicó The International Migration Review en 2006. Vid. la presentación del mismo en Donato et alt. (2006). Muy ilustrativo el texto de Poggio y Woo (2000).

EMPIRIA. Revista de Metodología de Ciencias Sociales. N. ${ }^{\circ}$ 19, enero-junio, 2010, pp. 39-71.

ISSN: 1139-5737 
transnacional ha sido inicialmente descrita a partir de los estudios de comunidades campesinas del interior de México. (Vid. por ejemplo Massey, Goldring y Durand: 1994, Poggio y Woo: 2000, y especialmente Oral: 2006). Al analizar dichas familias se ha observado que las estrategias de subsistencia de las mismas están basadas en el desplazamiento de parte de sus miembros, generalmente hacia USA, sin que ello haga perder el carácter familiar ni la vinculación de los emigrantes con las comunidades de origen. Los miembros desplazados vuelven, por ejemplo, con motivo de fiestas locales señaladas, se casan por lo general en la localidad de nacimiento y lo hacen con miembros de la propia comarca de origen. Oral (2006) analiza los cambios en las propias comunidades de origen, las cuales también muestran simbólicamente la transnacionalidad de sus habitantes. En este sentido por ejemplo, Kandel y Massey (2002) señalan la incorporación de la cultura de la migración como rito de paso para la juventud en las áreas de emigración.

Los análisis de género han mostrado también que existen mecanismos de reciprocidad en el cuidado de miembros familiares entre locales y emigrados. Es decir son familias que, aunque separadas en el espacio, siguen manteniendo relaciones domésticas. (Oral, 2006) Este hecho ha sido descrito también en África respecto a los miembros desplazados a Europa (Vid. Fleischer: 2007).

La familia transnacional es un grupo doméstico separado en el espacio, a veces presente en dos o incluso más continentes. Su origen reside en las economías de subsistencia campesinas, que en el mundo global de mercado, necesitan ahora del desplazamiento de miembros jóvenes a mercados salariales, mercados que por lo general sólo existen en lugares alejados, como estrategia para compatibilizar, mediante la obtención de rentas monetarias, su autosuficiencia en la sociedad de mercado.

La familia transnacional como grupo doméstico aunque repartido en el espacio altera los mecanismos de la propia organización y división familiar. El poder económico y decisorio se traslada a los miembros desplazados a la vez que cambian los sistemas de cuidado familiar que se trasladan hacia los miembros no desplazados. Esto último supone que la familia transnacional configura una red amplia en la que se engloba la familia nuclear. En los lugares de origen actúa mediante la extensión de los cuidados a miembros del grupo nuclear no desplazados, mientras que en destino actúa como red de acogida de los miembros de los núcleos desplazados incluyendo en algunos casos otras redes familiares extensas y/o locales. La familia transnacional, a pesar de la separación, se caracteriza por la fortaleza y permanencia de los vínculos afectivos. (Parella, 2007).

En el contexto de la globalización la familia transnacional es una pieza básica de lo que algunos autores comienzan a denominar etnofragmentación so$\mathrm{cial}^{2}$. Las sociedades etnofragmentadas se generan por el proceso de discrimi-

${ }^{2}$ Basado en la observación de Piore (1979) de cómo los empleadores seleccionan trabajadores extranjeros para distintas actividades, Pedreño (2005a) ha propuesto el término de sociedades et- 
nación de los mercados de trabajo en función del binomio de género y etnia. Frente a la idea simple de mercados de trabajo que consisten en la libre concurrencia entre oferta y demanda de empleo existe una creciente adscripción entre ocupaciones y las respectivas posiciones sociales a las que dan lugar determinadas por las características de inmigrante y género.

\section{METODOLOGÍA}

La ENI (Encuesta Nacional de Inmigración) es una encuesta representativa del conjunto de extranjeros residentes en España realizada por el Instituto Nacional de Estadística. Su amplio tamaño muestral, más de 15.000 viviendas encuestadas, con información sobre todos los residentes en ellas, así como la amplitud del cuestionario utilizado, que incluye datos sobres sus familias en origen, permite situar al inmigrante dentro del hogar y de la historia familiar. En total la ENI ha estimado que en 2007 residen en España más de cuatro millones y medio de inmigrantes ${ }^{3}$ lo que equivale al $12 \%$ del conjunto de habitantes mayores de 16 años de España. La tabla 1 refleja los datos obtenidos según grandes regiones de procedencia ${ }^{4}$ basadas en un criterio geográfico, criterio, que como podrá observarse a lo largo del texto, permite reconocer distintos modelos migratorios.

Sin embargo, aunque dispongamos de datos más completos y también más actuales para observar la composición y las estrategias de convivencia transnacional con más detalle, también existen importantes limitaciones en la fuente utilizada. Por ejemplo, para ciertos colectivos de presencia reducida los errores estadísticos son importantes de forma que en el análisis realizado se han omitido ciertos grupos (resto de Europa, América del Norte y Oceanía). No obstante en las tablas siguientes bajo la rúbrica de total además de los grupos especificados en la tabla se incluyen también a los procedentes de estas regiones.

En lo que respecta a este texto la existencia de pareja, cuando no se está casado, es el punto débil del análisis. Si bien pareja y cónyuge son categorías so-

nofragmentadas ampliando la selección del reclutamiento mediante los atributos de género y etnia al funcionamiento de las sociedades avanzadas. La etnia se constituye en elemento diferenciador de determinadas poblaciones que quedan así en situación inferior en cuanto a la distribución de los recursos sociales y ocupacionales. Recoge así las constataciones de Burawoy (1976) que muestra la internalización de la reproducción en las unidades domésticas. Así el «guetto» reproduce las condiciones domésticas de origen dado que los países centrales importan no sólo fuerza de trabajo sino también las propias condiciones de reproducción doméstica (barata) de las sociedades de origen. En este sentido la etnia se constituye en marcador, no sólo de la exclusión de actividades productivas sino en un sistema de segmentación social que afecta, por exclusión, a las condiciones de reproducción.

${ }^{3}$ La muestra de la ENI refiere como inmigrante a los extranjeros mayores de 16 años que no han nacido en España.

${ }^{4}$ La composición geográfica detallada puede consultarse en el anexo así como los datos absolutos por países de nacimiento de los extranjeros residentes en España. 
Tabla 1. Datos absolutos por regiones de procedencia y niveles de error estadístico

\begin{tabular}{lrrc}
\hline & $\begin{array}{c}\mathbf{N} \\
\text { Población } \\
\text { estimada }\end{array}$ & $\begin{array}{c}\mathbf{N} \\
\text { Tamaño } \\
\text { muestral }\end{array}$ & $\begin{array}{c}\text { N } \\
\text { Error de la proporción } \\
(\mathbf{p = 1 = 0 , 5} \text { para un nivel } \\
\text { de confianza del 95\% }\end{array}$ \\
\hline Sudamérica & 1.560 .532 & 5.273 & $1,3 \%$ \\
Centroamérica y Caribe & 227.160 & 905 & $3,3 \%$ \\
África Mediterránea & 601.477 & 2.075 & $2,2 \%$ \\
África Subsahariana & 166.111 & 494 & $4,4 \%$ \\
Europa del Este & 664.781 & 2.120 & $2,1 \%$ \\
Asia & 208.503 & 448 & $4,6 \%$ \\
UE-25 & 976.330 & 3.701 & $1,6 \%$ \\
Resto de Europa & 80.364 & 295 & $5,7 \%$ \\
América del Norte & 33.523 & 124 & $8,8 \%$ \\
Oceanía & 7.741 & 30 & $17,9 \%$ \\
\hline Total & 4.526 .522 & 15.465 & $0,8 \%$ \\
\hline
\end{tabular}

Fuente: ENI-2007.

ciológicamente equivalentes, únicamente se refieren a diferencias de ámbito legal, en la investigación realizada resulta complejo definir la pareja cuando no hay convivencia. Los miembros de un matrimonio pueden residir juntos o no y la encuesta así lo recoge. Sin embargo la definición de pareja, en un sentido idéntico al de cónyuge, sólo puede hacerse cuando se reside en el mismo domicilio. Es decir aquellas parejas no casadas en que un miembro reside en el país de origen desaparecen al análisis, y ello puede hacer que algunos inmigrantes con pareja en el lugar de origen aparezcan en cuanto a forma familiar como «sin núcleo». Esto afecta únicamente a aquéllas parejas no casadas y que no conviven, siempre y cuando no tengan hijos. En cuanto que existen hijos se consideran que tienen núcleo familiar. No obstante dado que alrededor de las tres cuartas partes de los entrevistados han constituido algún tipo de núcleo familiar no parece que este sesgo tenga efectos importantes en el análisis.

Otra cuestión importante es la selección y definición de la población a la que se refiere la investigación. En este sentido se han tomado dos decisiones. Por una parte se ha limitado la observación a aquellos inmigrantes que se han establecido en España durante la década 1996 y 2005, es decir se han omitido aquellos llegados hace tiempo y que por sus características socio-demográficas se corresponden con otras lógicas migratorias. También se ha establecido un tiempo de residencia de al menos un año para poder observar un periodo mínimo de asentamiento.

Dado que se investigan estructuras familiares de convivencia se han buscado datos generacionalmente homogéneos. En concreto se han seleccionado a 
aquellos de entre 20 y 44 años, de manera que se consiguiera tener un grupo bastante parecido en cuanto a su probabilidad de tener hijos menores. Además, la selección de edades realizada hace que la población estudiada se corresponda de manera más fiel con los nuevos perfiles inmigratorios. Se evitan así las interferencias de la numerosa población de Europa Occidental que residen en España, que cómo es sabido tienen otras lógicas migratorias ${ }^{5}$.

\section{MODELOS MIGRATORIOS EN ESPAÑA}

Como es conocido, España durante la última década ha asistido a un crecimiento notable de la población de origen inmigrante, población que procede de lugares muy diversos. No obstante, la distribución actual de los inmigrantes por nacionalidades (Vid. tabla 2) responde a distintos modelos migratorios independientes: Por un lado están las migraciones de retiro: jubilados centroeuropeos que encuentran en las áreas litorales de España condiciones de vida más agradables para su condición de inactividad. Se trata de una corriente migratoria que se desarrolla desde mediados de los 80 , y cuyos destinos están muy concentrados en comarcas, o incluso en pueblos, muy localizados ${ }^{6}$. Otra fuente de inmigración es el retorno de descendientes de emigrantes, retorno que en momentos de crisis en los lugares de procedencia puede ser intenso. Hijos o incluso nietos de emigrantes vuelven y se asientan en lugares en los que mantienen todavía lazos familiares. Este tipo de inmigración procedente desde Latinoamérica, (Argentina, Venezuela, Colombia, Uruguay o Cuba principalmente), y también de Centroeuropa (Suiza o Francia) que, por ejemplo, tiene especial importancia en algunas regiones rurales de Galicia ${ }^{7}$.

Más recientemente, durante la segunda mitad de la década de los 90, se generaliza la llegada de población inmigrante en edades activas a España desde distintos puntos del globo ${ }^{8}$. Es una inmigración muy ligada al desarrollo económico y a las expectativas de desarrollo vital de sus protagonistas.

${ }^{5}$ Nos referimos fundamentalmente a lo que se han venido denominando migraciones de retiro.

${ }^{6}$ Varios ejemplos vienen a la mente de todos, Mojácar en el litoral de Almería o Finestrat en Alicante, pequeñas poblaciones del archipiélago Balear. Valga como muestra del impacto, importante aunque local, de la migración de retiro, que, en 2001, en los municipios menores de 10000 habitantes en Alicante el 15,9\% de sus habitantes mayores de 65 años eran extranjeros.

${ }^{7}$ La correspondencia con los lugares de destino de las migraciones transoceánicas de finales del XIX y durante mediados del siglo XX es patente. Por ejemplo en las áreas rurales de Coruña, el $5 \%$ de los extranjeros es Suizo, en Orense el $7 \%$ de los extranjeros rurales procede de Venezuela, en Pontevedra los Argentinos son el 9\% de la población extranjera que reside en áreas rurales. Los colombianos son en el total de la Galicia rural el $9 \%$ de los extranjeros. Todas estas nacionalidades tienen por lo general un peso bastante menor en el conjunto de extranjeros en España. (Datos procedentes del Censo de Población, 2001. INE).

${ }^{8}$ Cachón (2002) señala el año 2000 como el comienzo de una tercera fase expansiva en la recepción de inmigrantes asociada a la globalización social y económica de España. 
Tabla 2. Distribución de los extranjeros residentes en España (2007)

\begin{tabular}{lr}
\hline \multicolumn{2}{c}{ Principales países de nacimiento } \\
\hline Marruecos & $11,9 \%$ \\
Rumanía & $9,5 \%$ \\
Ecuador & $8,2 \%$ \\
Colombia & $6,6 \%$ \\
Reino Unido & $6,0 \%$ \\
Argentina & $5,1 \%$ \\
Francia & $4,5 \%$ \\
Alemania & $3,5 \%$ \\
Bolivia & $3,5 \%$ \\
Perú & $3,1 \%$ \\
Venezuela & $2,3 \%$ \\
Bulgaria & $2,2 \%$ \\
Portugal & $1,9 \%$ \\
Brasil & $1,8 \%$ \\
Cuba & $1,8 \%$ \\
República Dominicana & $1,8 \%$ \\
Uruguay & $1,8 \%$ \\
Ucrania & $1,5 \%$ \\
Italia & $1,3 \%$ \\
Suiza & $1,2 \%$ \\
China & $1,2 \%$ \\
Chile & $1,2 \%$ \\
Argelia & $1,2 \%$ \\
Polonia & $1,0 \%$ \\
Filipinas & $1,0 \%$ \\
Otros & $14,8 \%$ \\
\hline
\end{tabular}

Fuente: ENI. 2007. INE.

En trabajos anteriores (Camarero y García: 2004, Camarero 2010) se habían analizado las diferencias familiares de asentamiento de los inmigrantes en España observándose distintos modelos en función de las áreas de origen. Modelos que afectaban especialmente a la composición demográfica y que sugerían precisamente la adaptación de la composición y de las estructuras familiares a la importancia de la movilidad transnacional. Las importantes diferencias observadas en cuanto a sexo en la composición demográfica se relacionaban claramente con las formas familiares de convivencia.

Con los datos de la ENI se pueden examinar estos modelos migratorios con más detalle y contrastarlos con los de otras regiones de procedencia que no habían sido caracterizadas en los trabajos anteriores. El gráfico 1 permite observar la distinta composición demográfica del colectivo inmigrante por regiones de procedencia. Por edades las diferencias no son grandes, entre los 20 y los 30 
años se concentra de forma notable el grueso de los inmigrantes, con la excepción de los procedentes de la UE-25 en donde resulta también visible el peso que tienen los prejubilados y jubilados. Sin embargo, como muestra el gráfico 1, las diferencias son grandes especialmente en cuanto a la composición por sexo (tabla 3). Se observa una fuerte masculinización en los grupos procedentes de África y Asia, un mayor equilibrio en los grupos europeos y la feminización de los grupos procedentes de Latinoamérica. Incluso podemos detectar una creciente feminización de la inmigración americana cada vez más visible en las edades jóvenes de las personas de procedencia sudamericana, algo perceptible también en la población asiática.

Tabla 3. Relación por sexo de los inmigrantes

\begin{tabular}{lcc}
\hline & Hombres & Mujeres \\
\hline Sudamérica & $46,2 \%$ & $53,8 \%$ \\
Centroamérica y Caribe & $36,9 \%$ & $63,1 \%$ \\
África Mediterránea & $65,9 \%$ & $34,1 \%$ \\
África Subsahariana & $74,8 \%$ & $25,2 \%$ \\
Europa Este & $52,9 \%$ & $47,1 \%$ \\
Asia & $67,3 \%$ & $32,7 \%$ \\
UE25 & $52,5 \%$ & $47,5 \%$ \\
\hline Total & $52,7 \%$ & $47,3 \%$ \\
\hline
\end{tabular}

Nota: Llegados entre 1996 y 2005, entre 20-44 años.

Fuente: ENI, 2007. Elaboración propia.

La feminización de las migraciones aunque es un fenómeno creciente no por ello es un fenómeno reciente. Trager (1984) o Lauby y Stark (1988) al analizar las migraciones rurales en Filipinas observaron con claridad que la emigración de dichas regiones era fundamentalmente femenina. Este hecho lo explicaban por la desvalorización que en origen tenía el trabajo femenino. Este fenómeno ya había sido destacado con anterioridad por Boserup 9 (1970) aunque en su explicación no se habían incorporado a las estrategias familiares. En el caso de Fili-

${ }^{9}$ Esta autora encontró una relación entre las diferencias en las tasas de actividad de las mujeres en el campo y la ciudad, y las tasas diferenciales de emigración femenina. Por ejemplo en Latinoamérica observó un contraste entre baja tasa de actividad femenina rural y alta tasa urbana, mientras en África se apreciaba la situación contraria. Así establece tres causas que intervienen en las diferencias migratorias. Una de ellas es la existencia de oportunidades económicas en las ciudades; otra la fuerte vinculación a la actividad agraria - por ejemplo en África, en donde las migraciones campo-ciudad están masculinizadas - y añadirá una tercera, pensando en el caso asiático, que tiene que ver con los constreñimientos culturales a la movilidad. 
Gráfico 1. Estructuras demográficas por región de procedencia

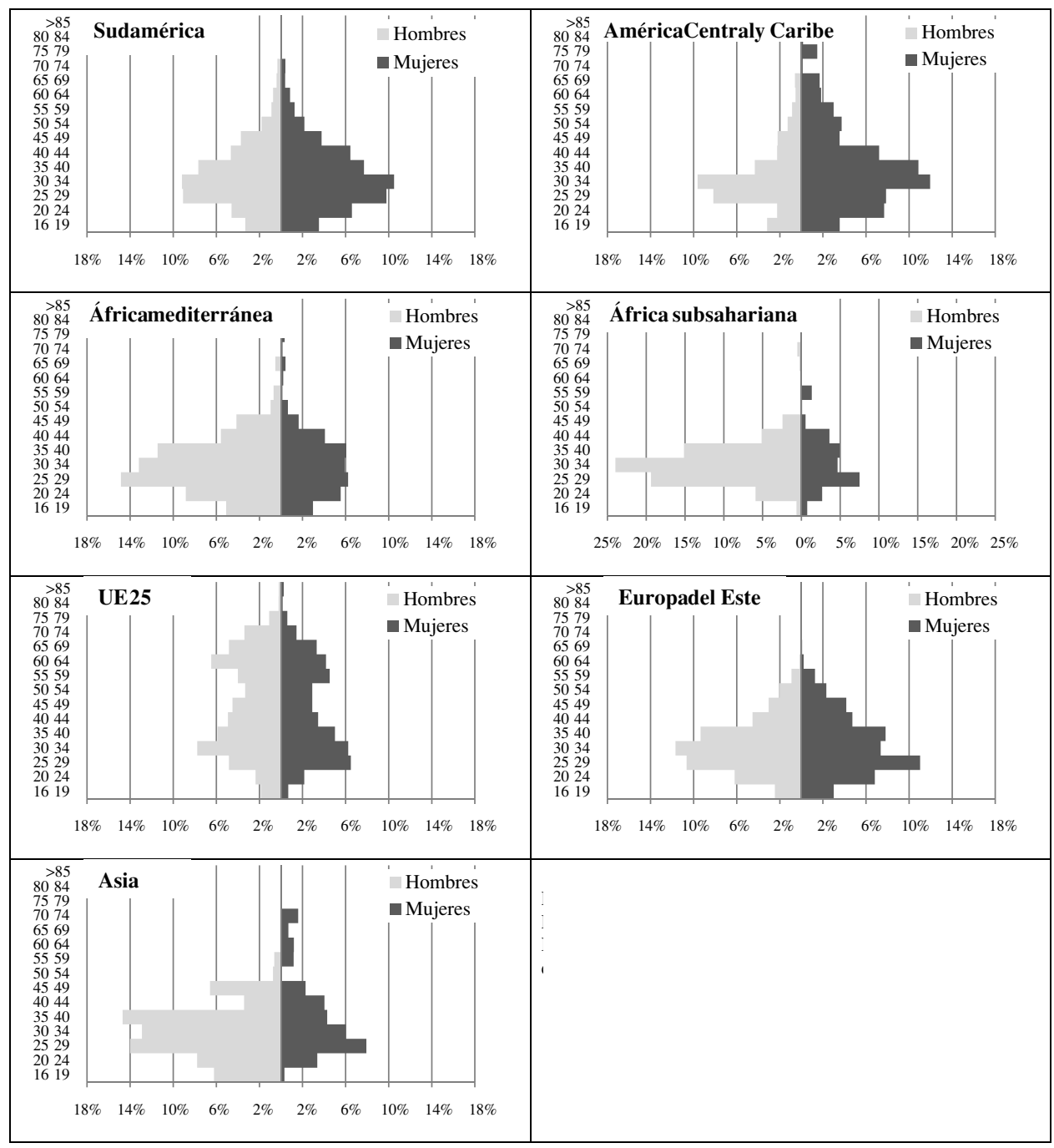

Fuente: ENI, 2007. INE.

Llegados entre 1996 y 2005.

Nota: El gráfico de Affrica Subsahariana tiene otra escala y no es directamente comparable con el resto. 
pinas las autoras Lauby y Stark consideran que, además de la subsidiariedad económica en la que generalmente se posicionan las mujeres y que agiliza su incorporación en mercados laborales fuertemente irregulares y precarizados, es también su fuerte dependencia respecto del conjunto familiar lo que explica en mayor medida la importante emigración femenina. La dependencia de las mujeres respecto a la familia persiste aun en el caso de que estén desplazadas. La emigración femenina garantiza que la familia de origen reciba parte de los ingresos del emigrante, algo que no sucedería en la misma proporción si emigraran los varones.

Mientras que la ya clásica teoría de la causación acumulativa de las migraciones (Massey et alt.: 1998) señala que la emigración se generaliza en origen extendiéndose a todos los miembros de la comunidad ahora se añade una alta selectividad, como muestra la feminización de la emigración transnacional (Pedreño: 2005a). Se produce una especialización de grupos migratorios en torno a los que se produce la difusión de la experiencia migratoria. En este sentido la simple «generización» de las corrientes migratorias está indicando la existencia e importancia de la organización familiar de las migraciones. Estudios como los realizados por Pedone (2003) muestran el funcionamiento de las cadenas migratorias según los mecanismos de adscripción a la estructura social (género o edad) pero señala especialmente la regulación de dichas cadenas a través de la familia. El trabajo de Suárez y Crespo (2007) pone de relieve el papel de las rumanas en la organización familiar de las migraciones.

Como se verá, precisamente la proporción por sexo de los inmigrantes aparece continuamente relacionada con los distintos modelos familiares, tanto en origen como en destino. Conviene, no obstante, aclarar que cuando se habla de feminización migratoria se refiere al arranque de las cadenas migratorias, como se verá al final del texto, los procesos de reagrupación familiar inciden posteriormente en la emigración masculina de forma que con el paso del tiempo se difumina en algunos casos la composición asimétrica de las corrientes migratorias en cuanto a sexo.

Izquierdo y León-Alfonso (2008) señalan que el proceso de reagrupación familiar muestra en la madurez del ciclo de instalación. Estos autores auguran, en el caso de España, un incremento de las migraciones no económicas, es decir familiares, e incluso destacan cómo dicho proceso de reagrupación tiende a corregir los importantes desequilibrios demográficos que producen las primeras corrientes migratorias. Precisamente es en este momento de madurez en el que se encuentran los ciclos migratorios en España y por ello mismo la importancia que tiene el análisis de las estructuras familiares.

\section{ESTRUCTURAS FAMILIARES TRANSNACIONALES}

Sobre el modelo de la familiar nuclear (padres más hijos) y de tamaño reducido como estructura de hogar más común en las sociedades del Norte y del 
Oeste de Europa, contrastaremos las formas familiares nucleares de los distintos colectivos. Como núcleo familiar consideraremos la forma más reducida del mismo el grupo compuesto por la pareja, si la hay, y los hijos, si los hubiera. Es decir un núcleo viene determinado por la existencia de pareja y/o hijos. Existen por tanto tres modalidades de núcleo: pareja con hijos, pareja sin hijos y, padre o madre sin pareja y con hijos - formas monoparentales - . Como hijos únicamente se consideran los menores de 16 años ${ }^{10}$. El núcleo familiar así definido se relaciona con las formas de convivencia. Si consideramos el hogar como el conjunto de personas que habitan en el mismo domicilio podemos analizar la coincidencia entre núcleo familiar y hogar — cuando todos los miembros del núcleo residen en el mismo hogar - o la separación del núcleo entre distintos hogares. Esta relación, entre núcleo familiar y domicilio, es la que mostrará la existencia de la familia transnacional. La familia transnacional la podemos definir como los núcleos familiares que no conviven en un único hogar siempre y cuando uno de los hogares pertenezca a un país diferente.

La tabla 4 nos muestra la estructura familiar nuclear en la que se insertan los inmigrantes. Como puede observarse los procedentes de África y Asia, que por lo general se corresponden con corrientes migratorias más masculinizadas tienen menor peso los núcleos familiares. Por el contrario los procedentes de América Latina, corrientes más feminizadas, tienen mayor incidencia de formas familiares monomarentales que en el resto.

Tabla 4. Formas familiares nucleares

\begin{tabular}{|c|c|c|c|c|c|c|c|c|}
\hline & 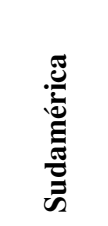 & 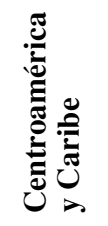 & 苞莺 & & 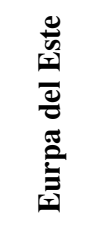 & $\frac{\pi}{2}$ & $\begin{array}{l}\stackrel{2}{1} \\
\text { 帘 }\end{array}$ & है \\
\hline Sin núcleo familiar & $19,5 \%$ & $15,5 \%$ & $33,9 \%$ & $31,9 \%$ & $21,3 \%$ & $37,3 \%$ & $23,8 \%$ & $23,4 \%$ \\
\hline Pareja sin hijos & $17,9 \%$ & $21,4 \%$ & $18,2 \%$ & $14,7 \%$ & $27,9 \%$ & $13,9 \%$ & $29,5 \%$ & $21,1 \%$ \\
\hline Pareja con hijos & $51,8 \%$ & $50,2 \%$ & $45,9 \%$ & $47,9 \%$ & $47,0 \%$ & $47,3 \%$ & $41,9 \%$ & $46,5 \%$ \\
\hline Monoparental & $10,8 \%$ & $12,9 \%$ & $2,0 \%$ & $5,5 \%$ & $3,8 \%$ & $1,4 \%$ & $4,8 \%$ & $6,9 \%$ \\
\hline TOTAL & $100 \%$ & $100 \%$ & $100 \%$ & $100 \%$ & $100 \%$ & $100 \%$ & $100 \%$ & $100 \%$ \\
\hline
\end{tabular}

Nota: Llegados entre 1996 y 2005, entre 20-44 años.

Fuente: ENI, 2007. Elaboración propia.

${ }^{10}$ De esta forma se evitan las situaciones en las que los hijos pueden haber abandonado el núcleo familiar para constituir uno propio, ya que las edades de emancipación familiar resultan cultural y socialmente muy variables.

EMPIRIA. Revista de Metodología de Ciencias Sociales. N. ${ }^{\text {19 }}$, enero-junio, 2010, pp. 39-71. ISSN: 1139-5737 
Para llegar a valorar la transnacionalidad familiar estudiaremos a continuación, las formas de convivencia de los núcleos familiares. Primero lo haremos respecto a la existencia de pareja, y posteriormente añadiremos la existencia de hijos menores, para finalmente llegar a analizar la situación en su conjunto del núcleo.

Respecto a las formas de convivencia en pareja se presentan tres situaciones distintas; no tiene cónyuge o pareja, tiene pareja o cónyuge y convive con él y, por último, tiene cónyuge pero no convive con él o ella. Esta última categoría pertenece a la familia transnacional: parejas separadas en su convivencia doméstica. En el caso de matrimonios o parejas que conviven se han especificado también las relaciones entre la nacionalidad de ambos cónyuges para generar tres tipos de pareja; Intranacional cuando ambos cónyuges tienen la misma nacionalidad, internacional, cuando tienen nacionalidades distintas y mixto cuando uno de los cónyuges es Español.

Tabla 5. Inmigrantes de 20 a 45 según las características de su cónyuge o pareja

\begin{tabular}{|c|c|c|c|c|c|c|c|c|c|}
\hline & & 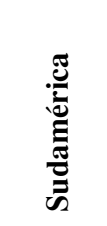 & 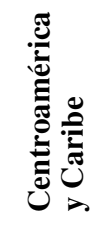 & 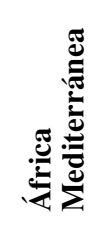 & 蒠 & 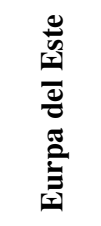 & $\frac{\frac{\pi}{2}}{2}$ & $\begin{array}{l}\text { 先 } \\
\text { 帘 }\end{array}$ & 晃 \\
\hline \multicolumn{2}{|c|}{ No casado/sin pareja } & $29,0 \%$ & $27,7 \%$ & $35,1 \%$ & $37,4 \%$ & $24,5 \%$ & $36,9 \%$ & $28,4 \%$ & $29,4 \%$ \\
\hline Convive & Matrimonio intranac. & $49,5 \%$ & $27,2 \%$ & $44,8 \%$ & $19,1 \%$ & $63,9 \%$ & $34,5 \%$ & $30,9 \%$ & $46,6 \%$ \\
\hline con su & Matrimonio internac. & $5,5 \%$ & $6,1 \%$ & $1,4 \%$ & $9,4 \%$ & $1,2 \%$ & $4,2 \%$ & $14,4 \%$ & $5,2 \%$ \\
\hline pareja & Mixto & $11,0 \%$ & $30,5 \%$ & $4,4 \%$ & $6,6 \%$ & $7,0 \%$ & $5,9 \%$ & $25,0 \%$ & $11,4 \%$ \\
\hline \multicolumn{9}{|c|}{ No convive con el cónyuge } & $0,9 \%$ \\
\hline \multicolumn{2}{|c|}{ El cónyuge vive en el extranjero } & $3,8 \%$ & $7,8 \%$ & $13,6 \%$ & $27,4 \%$ & $3,0 \%$ & $16,7 \%$ & $1,1 \%$ & $6,4 \%$ \\
\hline \multicolumn{2}{|l|}{ TOTAL } & $100 \%$ & $100 \%$ & $100 \%$ & $100 \%$ & $100 \%$ & $100 \%$ & $100 \%$ & $100 \%$ \\
\hline
\end{tabular}

Nota: Llegados entre 1996 y 2005, entre 20-44 años.

Fuente: ENI, 2007. Elaboración propia.

Los modelos de inmigración masculinizada como son los procedentes de África y Asia presentan unas tasas elevadas de separación residencial de las parejas. Entre una sexta parte, en el caso de África Mediterránea y Asia, y una cuarta parte, entre los procedentes del África Subsahariana, tienen a su cónyuge en el país de origen. Los inmigrantes procedentes de Latinoamérica mantienen mayores tasas de convivencia conyugal, no obstante conviene observar la importancia que tienen los matrimonios mixtos en el caso de las migraciones más feminizadas como son las procedentes de Centroamérica. Por sexo, dichas dife- 
rencias son aún más evidentes y más de la tercera parte de los hombres africanos y asiáticos casados tienen a su cónyuge en el país de origen, cifra que resulta muy elevada (más del 25\%) en el caso de los subsaharianos.

$\mathrm{Si}$ atendemos al sexo observamos que las inmigrantes casadas conviven casi en su totalidad con su pareja con la ligera excepción de centroamericanas y asiáticas (tabla 6) En el caso de Centroamérica, que recordemos se trata de una emigración más feminizada y con un contexto de organización familiar menos anclado en el matrimonio como institución de convivencia, esta situación, probablemente, indique que aunque legalmente ellas estén casadas, en la práctica, no exista relación de pareja. Para Asia los resultados resultan relativamente sorprendentes porque las proporciones de separación residencial de las parejas son comparativamente altas tanto para hombres como para mujeres. Ello es resultado de la importante heterogeneidad en la procedencia de nacionalidades de este grupo, único continente que no se ha diferenciado por regiones debido a su menor número de efectivos, que en sus datos globales encierra las migraciones masculinizadas de India o Pakistán y las más feminizadas y anteriormente comentadas en la literatura de Filipinas y del Asia más suroriental.

Tabla 6. \% de casados cuyo cónyuge reside en el extranjero

\begin{tabular}{|c|c|c|c|c|c|c|c|c|}
\hline & 氖 & 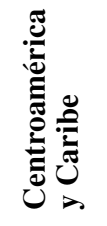 & 践 & 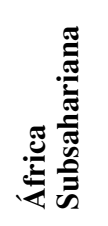 & 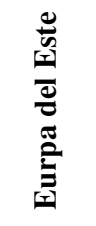 & $\frac{\frac{\pi}{2}}{2}$ & 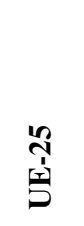 & 吾 \\
\hline Hombres & $6,5 \%$ & $15,5 \%$ & $35,2 \%$ & $61,0 \%$ & $6,1 \%$ & $39,0 \%$ & $1,6 \%$ & $14,7 \%$ \\
\hline Mujeres & $4,2 \%$ & $8,1 \%$ & $2,4 \%$ & $4,1 \%$ & $1,8 \%$ & $8,9 \%$ & $1,4 \%$ & $3,5 \%$ \\
\hline Total & $5,3 \%$ & $10,8 \%$ & $20,9 \%$ & $43,8 \%$ & $4,0 \%$ & $26,4 \%$ & $1,5 \%$ & $9,1 \%$ \\
\hline
\end{tabular}

Nota: Llegados entre 1996 y 2005, entre 20-44 años.

Fuente: ENI, 2007. Elaboración propia.

La tabla anterior (tabla 6), aunque sólo se refiere a las parejas, ya nos orienta sobre el carácter transnacional de los núcleos familiares. Podemos decir que las parejas transnacionales suponen más de la quinta parte de los procedentes de África, cifra que llega al $40 \%$ en el caso de los subsaharianos, y más de la cuarta parte de los asiáticos. Estas cifras contrastan con la casi inexistente separación residencial de las parejas que se observa entre los procedentes de la Europa de los 25 .

Evidentemente las cifras de transnacionalidad se amplían al tener en cuenta a los hijos menores del núcleo familiar. El análisis de los núcleos con hijos 
complejiza sin embargo el análisis en la medida en que se mezcla el propio ciclo familiar con el ciclo migratorio, produciéndose una importante diversidad de situaciones. Así pueden existir en las parejas actuales hijos procedentes de matrimonios anteriores, o también puede darse el caso en que parte de los hijos han nacido en el lugar de origen y otra parte han nacido en el lugar de destino.

Por lo general la mitad de los inmigrantes tiene algún hijo menor de 16 años aunque entre los latinoamericanos la cifra es más elevada, siendo estos un poco más de las dos terceras partes (tabla 7). Este dato sugiere, para este grupo, que por lo general la formación del núcleo familiar antecede al proyecto migratorio. Aspecto que podremos comprobar con mayor precisión en la parte final del texto.

Tabla 7. $\%$ de inmigrantes que tienen hijos menores de 16 años

\begin{tabular}{|c|c|c|c|c|c|c|c|c|}
\hline & 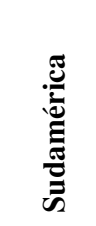 & 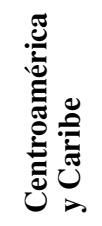 & 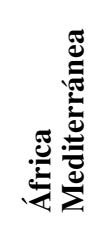 & 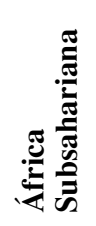 & 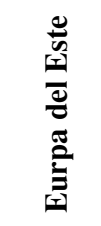 & $\frac{\pi}{\frac{\pi}{2}}$ & 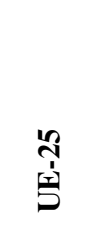 & : \\
\hline No tiene hijos menores de 16 años & $37,3 \%$ & $36,8 \%$ & $52,2 \%$ & $46,6 \%$ & $49,2 \%$ & $51,2 \%$ & $53,3 \%$ & $44,6 \%$ \\
\hline Tiene hijos menores de 16 años & $62,7 \%$ & $63,2 \%$ & $47,8 \%$ & $53,4 \%$ & $50,8 \%$ & $48,8 \%$ & $46,7 \%$ & $55,4 \%$ \\
\hline
\end{tabular}

Nota: Llegados entre 1996 y 2005, entre 20-44 años.

Fuente: ENI, 2007. Elaboración propia.

La tabla 8, que distingue los hijos en función del lugar de residencia, señala el carácter familiar de la inmigración Sudamericana o de Europa del Este. En ambos casos los hijos residen con los padres, esta situación contrasta con los inmigrantes procedentes de Centroamérica y del África subsahariana para quienes sus hijos, menores de 16 años, siguen viviendo en los lugares de origen. No obstante, de forma general, las tasas de separación entre el inmigrante y sus hijos son elevadas, una cuarta parte de los extranjeros mantiene algún hijo menor en el lugar de origen.

Hay que tener en cuenta que algunos núcleos se han formado antes de la emigración y otros que se han compuesto en destino años después de la migración. En un sentido más preciso sólo, en los primeros tipos de núcleo, sería posible hablar de transnacionalidad ${ }^{11}$. Por ello, una medida más adecuada al fenómeno es referir los datos a aquéllos núcleos cuyos menores han nacido en origen como refleja la tabla 9.

${ }^{11}$ No obstante, debe tenerse en cuenta que existen distintas estrategias en las familias transnacionales, y una de ellas es la desagrupación familiar ilustrada por los trabajos de García Borrego

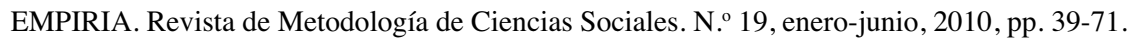

ISSN: 1139-5737 
Tabla 8. Lugar de residencia de los hijos menores de 16 años

\begin{tabular}{|c|c|c|c|c|c|c|c|c|}
\hline & 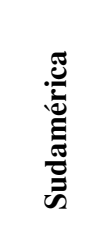 & 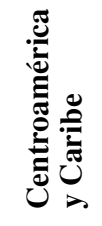 & 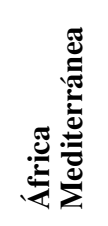 & 焉 & 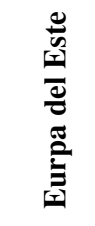 & $\frac{\frac{\pi}{2}}{2}$ & 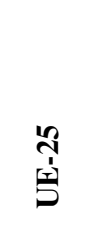 & हैं \\
\hline $\begin{array}{l}\text { Todos están en España y viven } \\
\text { con él }\end{array}$ & $68,9 \%$ & $60,4 \%$ & $84,9 \%$ & $33,7 \%$ & $81,3 \%$ & $63,9 \%$ & $88,0 \%$ & $72,7 \%$ \\
\hline Todos están en el lugar de origen & $22,0 \%$ & $32,2 \%$ & $11,7 \%$ & $53,6 \%$ & $15,8 \%$ & $30,0 \%$ & $8,6 \%$ & $20,6 \%$ \\
\hline $\begin{array}{l}\text { Algunos están en España } \\
\text { y otros en el lugar de origen }\end{array}$ & $6,9 \%$ & $7,1 \%$ & $1,5 \%$ & $12,0 \%$ & $1,8 \%$ & $4,1 \%$ & $1,9 \%$ & $4,9 \%$ \\
\hline $\begin{array}{l}\text { Todos están en España } \\
\text { pero ninguno vive con él }\end{array}$ & $2,2 \%$ & $0,3 \%$ & $1,9 \%$ & $0,7 \%$ & $1,2 \%$ & $2,1 \%$ & $1,5 \%$ & $1,8 \%$ \\
\hline TOTAL & $100 \%$ & $100 \%$ & $100 \%$ & $100 \%$ & $100 \%$ & $100 \%$ & $100 \%$ & $100 \%$ \\
\hline
\end{tabular}

Nota: Llegados entre 1996 y 2005, entre 20-44 años.

Fuente: ENI, 2007. Elaboración propia.

Tabla 9. Lugar de residencia de los hijos menores de 16 años de los inmigrantes (Ninguno de su hijos ha nacido en España)

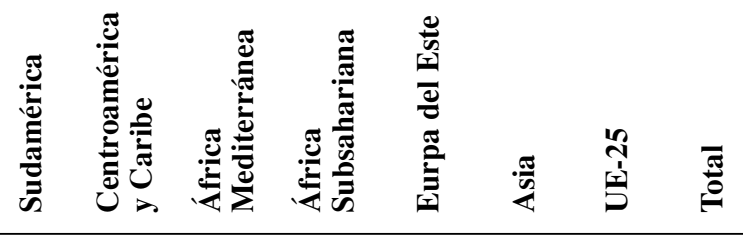

Todos están en España y viven con él

$54,9 \% \quad 41,1 \% \quad 57,1 \% \quad 10,9 \% \quad 72,5 \% \quad 43,9 \% \quad 78,9 \% \quad 57,5 \%$

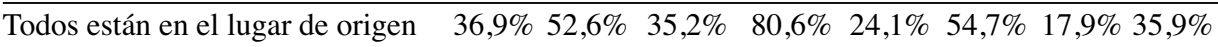

Algunos están en España

$\begin{array}{lllllllll}\text { y otros en el lugar de origen } & 4,6 \% & 5,7 \% & 1,7 \% & 8,5 \% & 1,7 \% & 0,9 \% & 0,7 \% & 3,6 \%\end{array}$

Todos están en España

pero ninguno vive con él

\begin{tabular}{lllllllll}
\hline TOTAL & $100 \%$ & $100 \%$ & $100 \%$ & $100 \%$ & $100 \%$ & $100 \%$ & $100 \%$ & $100 \%$
\end{tabular}

Nota: Llegados entre 1996 y 2005, entre 20-44 años.

Fuente: ENI, 2007. Elaboración propia. 
Estos datos muestran de forma más precisa la situación de separación paterno-filial que implica la emigración. Se observa que realmente un 50\% de los núcleos constituidos antes de la emigración tienen algún hijo menor que reside en el lugar de origen. No obstante, las diferencias entre regiones de origen son grandes. Los procedentes de Europa tienen tasas de convivencia entre padres e hijos altas mientras que esto sólo sucede entre uno de cada diez subsaharianos.

Hay que tener en cuenta que estos datos sólo se refieren a aquéllos que tienen hijos menores. Así, el dato que más de la mitad de quienes proceden de África mediterránea conviven con sus hijos se refiere únicamente a quienes han formado un núcleo, sin embargo, comparativamente con otras regiones son quienes menos han formado núcleos (tabla 5). Por ello la información que nos ofrece la tabla debe interpretarse como el grado de unidad residencial paternofilial que se produce cuando se forman núcleos. De forma más completa se puede observar en la siguiente tabla la fragmentación de los núcleos familiares en relación con los grupos domésticos. Es decir la relación entre núcleo y convivencia familiar.

La tabla 10 nos muestra claramente dos modelos de estructuras y convivencia familiar que se corresponden con la relación entre sexos que se produce en las corrientes migratorias. Así, las migraciones más masculinizadas no han llegado a formar núcleo familiar; la tercera parte de los africanos y asiáticos. Por el contrario en las migraciones más feminizadas la existencia de núcleo es mayor. Pero además, y con independencia de lo anterior, existen importantes variaciones en el grado de unidad familiar. Sudamericanos y Europeos muestran llegan a tasas importantes de correspondencia entre núcleo y hogar. Alrededor del $40 \%$ de los inmigrantes están en hogares totalmente reagrupados. También sucede esto en el caso del África Mediterránea, que muestra una fuerte polaridad. O no hay núcleo o cuando lo hay sus miembros residen juntos.

(2008) y también referida por Parella y Samper (2007). La desagrupación se produce cuando los hijos nacidos en España son enviados posteriormente a los países de origen de los padres para vivir con otros familiares. Los datos muestran que numéricamente su impacto no es por lo general grande con la excepción de los procedentes del África Subsahariana cuya cifra se acerca al 5\%.

Índice de desagrupación de los hijos.

Porcentaje que tienen algún hijo menor de 16 años nacido en España que reside en el país de origen del padre. (Tienen algún hijo menor de 16 años.)

\begin{tabular}{ll}
\hline Sudamérica & $0,7 \%$ \\
Centroamérica y Caribe & $2,8 \%$ \\
África mediterránea & $0,8 \%$ \\
África subsahariana & $4,3 \%$ \\
Europa del Este & $0,7 \%$ \\
Asia & $2,7 \%$ \\
UE-25 & $0,5 \%$ \\
\hline Total & $1,1 \%$ \\
\hline
\end{tabular}

Nota: Llegados entre 1996 y 2005, entre 20-44 años.

Fuente: ENI, 2007. Elaboración propia. 
Tabla 10. Convivencia en el hogar del núcleo familiar

\begin{tabular}{|c|c|c|c|c|c|c|c|c|c|}
\hline & & 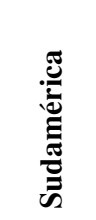 & 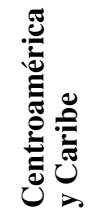 & 忍 & 焉 & 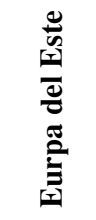 & 要 & 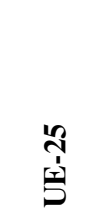 & हैं \\
\hline \multicolumn{2}{|c|}{ Sin núcleo familiar } & $19,5 \%$ & $15,5 \%$ & $33,9 \%$ & $31,9 \%$ & $21,3 \%$ & $37,3 \%$ & $23,8 \%$ & $23,4 \%$ \\
\hline \multirow{2}{*}{ Pareja sin hijos } & Todos aquí & $17,0 \%$ & $19,9 \%$ & $10,4 \%$ & $8,3 \%$ & $26,8 \%$ & $8,3 \%$ & $29,3 \%$ & $18,9 \%$ \\
\hline & Todos allí & $0,8 \%$ & $1,5 \%$ & $7,8 \%$ & $6,4 \%$ & $1,1 \%$ & $5,6 \%$ & $0,2 \%$ & $2,2 \%$ \\
\hline \multirow{3}{*}{ Pareja con hijos } & Todos aquí & $39,4 \%$ & $32,9 \%$ & $39,6 \%$ & $16,8 \%$ & $40,0 \%$ & $31,2 \%$ & $38,2 \%$ & $37,8 \%$ \\
\hline & Alguno allí & $10,2 \%$ & $12,3 \%$ & $0,8 \%$ & $11,2 \%$ & $5,4 \%$ & $5,1 \%$ & $3,1 \%$ & $7,1 \%$ \\
\hline & Todos allí & $2,2 \%$ & $5,1 \%$ & $5,4 \%$ & $19,9 \%$ & $1,6 \%$ & $11,1 \%$ & $0,6 \%$ & $3,7 \%$ \\
\hline \multirow{3}{*}{ Monoparental } & Todos aquí & $4,7 \%$ & $4,3 \%$ & $1,7 \%$ & $0,9 \%$ & $1,6 \%$ & $0,9 \%$ & $3,4 \%$ & $3,2 \%$ \\
\hline & Alguno allí & $0,6 \%$ & $0,9 \%$ & $0,2 \%$ & $0,2 \%$ & $0,1 \%$ & $0,0 \%$ & $0,1 \%$ & $0,3 \%$ \\
\hline & Todos allí & $5,5 \%$ & $7,7 \%$ & $0,0 \%$ & $4,4 \%$ & $2,1 \%$ & $0,5 \%$ & $1,3 \%$ & $3,4 \%$ \\
\hline \multicolumn{2}{|l|}{ Total } & $100 \%$ & $100 \%$ & $100 \%$ & $100 \%$ & $100 \%$ & $100 \%$ & $100 \%$ & $100 \%$ \\
\hline
\end{tabular}

Nota: Llegados entre 1996 y 2005, entre 20-44 años.

Fuente: ENI, 2007. Elaboración propia.

Si nos centramos en los núcleos existentes podemos obtener la medida buscada de transnacionalidad: la proporción de núcleos familiares que no residen en la misma vivienda. La última fila de la tabla 11 muestra la tasa de transnacionalidad es decir la proporción que suponen aquellos núcleos en los que al menos un miembro sigue en el país de origen. No obstante, como ya hemos observado en el caso de la convivencia de los hijos, no puede responderse esta cuestión de forma única en la medida en que existe una gran diversidad de situaciones en la formación de los núcleos en relación con los lugares de residencia entre los distintos miembros del núcleo ${ }^{12}$. Pero, a pesar de estas carencias, este indicador es una buena medida que nos aproxima a la realidad y a las diferencias en el impacto que tienen las familias transnacionales en el conjunto de la inmigración. Si observamos los datos globales, la importancia de la transnacionalidad es alta: sólo la mitad de los núcleos familiares residen juntos.

${ }^{12}$ El cónyuge puede ser español, o los hijos han podido nacer España, situaciones en las que no tendría sentido hablar de transnacionalidad. Pero también pueden producirse otras situaciones, hijos nacidos en España que residen en el país de origen de alguno de los padres, como vimos anteriormente. 
Tabla 11. Índice de transnacionalidad. Lugar de residencia de los miembros del núcleo familiar

\begin{tabular}{|c|c|c|c|c|c|c|c|c|}
\hline & 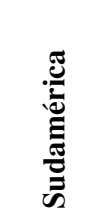 & 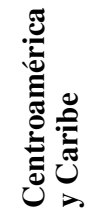 & 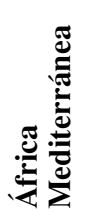 & 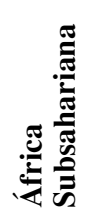 & 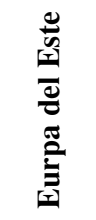 & 䨱 & 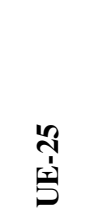 & 矛 \\
\hline Todos en España & $75,9 \%$ & $67,6 \%$ & $78,4 \%$ & $38,2 \%$ & $86,9 \%$ & $64,5 \%$ & $93,0 \%$ & $78,2 \%$ \\
\hline Alguno en origen & $13,4 \%$ & $15,6 \%$ & $1,5 \%$ & $16,7 \%$ & $7,0 \%$ & $8,1 \%$ & $4,2 \%$ & $9,1 \%$ \\
\hline Todos en origen & $10,7 \%$ & $16,8 \%$ & $20,1 \%$ & $45,1 \%$ & $6,1 \%$ & $27,4 \%$ & $2,8 \%$ & $12,1 \%$ \\
\hline TOTAL & $100 \%$ & $100 \%$ & $100 \%$ & $100 \%$ & $100 \%$ & $100 \%$ & $100 \%$ & $100 \%$ \\
\hline Transnacionalidad & $24,1 \%$ & $32,4 \%$ & $21,6 \%$ & $61,8 \%$ & $13,1 \%$ & $35,5 \%$ & $7,0 \%$ & $21,8 \%$ \\
\hline
\end{tabular}

Nota: Llegados entre 1996 y 2005, entre 20-44 años.

Fuente: ENI, 2007. Elaboración propia.

\section{FORMAS DE HOGAR}

Como hemos expuesto, las formas nucleares de familia, en el contexto de las familias transnacionales, no están necesariamente asociadas a la convivencia doméstica, pero ello no quiere decir que las formas de convivencia en destino no sean también familiares. Como podemos observar (tabla 12) un poco más del $40 \%$ de los inmigrantes residen en un hogar compuesto por un único núcleo - con o sin pareja o con o sin hijos -, aunque este puede ser, o no,

Tabla 12. Formas de convivencia de los inmigrantes

\begin{tabular}{|c|c|c|c|c|c|c|c|c|}
\hline & 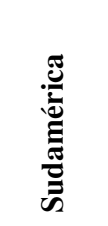 & 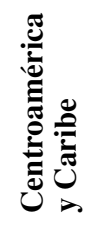 & 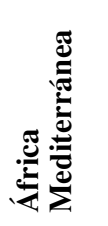 & 䒿 & 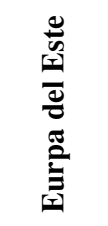 & $\frac{\frac{\pi}{2}}{2}$ & 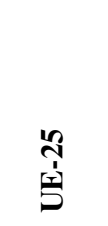 & 苞 \\
\hline Unipersonal & $2,9 \%$ & $4,9 \%$ & $4,6 \%$ & $4,5 \%$ & $2,4 \%$ & $6,3 \%$ & $10,2 \%$ & $4,1 \%$ \\
\hline Nuclear & $43,9 \%$ & $54,3 \%$ & $38,7 \%$ & $20,3 \%$ & $44,2 \%$ & $23,9 \%$ & $65.3 \%$ & $44,2 \%$ \\
\hline Polinuclear & $29,8 \%$ & $19,6 \%$ & $35,4 \%$ & $26,7 \%$ & $32,2 \%$ & $30,5 \%$ & $11,4 \%$ & $28,4 \%$ \\
\hline Otros & $15,2 \%$ & $12,3 \%$ & $5,5 \%$ & $13,4 \%$ & $13,4 \%$ & $15,2 \%$ & $4,3 \%$ & $12,1 \%$ \\
\hline Sin ningún núcleo & $8,2 \%$ & $9,8 \%$ & $15,8 \%$ & $35,1 \%$ & $7,8 \%$ & $24,2 \%$ & $8,7 \%$ & $11,2 \%$ \\
\hline
\end{tabular}

Nota: Llegados entre 1996 y 2005, entre 20-44 años.

Fuente: ENI, 2007. Elaboración propia. 
transnacional. Las principales diferencias aparecen en la categoría «sin ningún núcleo». Este grupo lo constituyen viviendas compartidas en las que no existe ninguna relación de parentesco entre ninguno de sus miembros. Estas viviendas son numéricamente importantes en los casos africano y asiático. Otros tipos de composición de la vivienda donde residen personas con relaciones familiares y personas sin relaciones familiares (categoría «otros» en la tabla) tienen un peso relativo a excepción de la UE-25 y del África Mediterránea.

Se observa especialmente la importancia que tiene la familia polinuclear como hogar que llega a tener los valores más elevados entre los procedentes del África mediterránea y de Europa del Este. El hecho de que más de la cuarta parte de los inmigrantes resida en hogares polinucleares, que recordemos no tienen porqué contener un núcleo completo, más la suma de los hogares nucleares supone que aproximadamente las tres cuartas partes de los inmigrantes residen en hogares de carácter eminentemente familiar. Estos datos pueden parecer contradictorios con la fragmentación territorial de los grupos domésticos nucleares que se ha venido constatando, sin embargo resulta consistente con la tesis de la familia transnacional. Se fragmentan los núcleos familiares entre origen y destino mientras adquieren una gran importancia las formas familiares extensas de red familiar. Es decir la familia transnacional fragmenta los núcleos basados en relaciones de parentesco primarias y afianza el carácter familiar extenso.

La movilidad transnacional debilita los núcleos familiares pero aumenta el peso y relevancia de la red familiar. Si bien la tendencia es hacia el reagrupamiento progresivo de la familia nuclear los porcentajes de residencia fragmentada entre los miembros del núcleo familiar son muy altos. Todo ello lo podemos observar de manera más detallada en el gráfico 2 que relaciona los tipos de núcleo familiar en función de las situaciones de reagrupamiento y las formas de hogar en destino según las distintas regiones de procedencia ${ }^{13}$. En el gráfico 2 se diferencian las situaciones más familiares, a la izquierda, de las individuales, a la derecha. Por otra las situaciones de menor reagrupamiento familiar, los núcleos más transnacionales, se sitúan abajo, frente a los menos transnacionales que lo hacen arriba. Los hogares polinuclerares en destino ocupan la posición central del cuadro, casi en el origen de ambas dimensiones. Esta posición central en un análisis de correspondencias refleja que dichos hogares están igual de presentes en cualquier situación. Es decir, con independencia del tipo de núcleo familiar y del grado de transnacionalidad del mismo, la convivencia en destino se realiza a través de hogares compuestos por redes familiares.

Por una parte la emigración retrasa, y tal vez dificulta, la formación familiar, especialmente en el caso de los modelos masculinizados - África y Asia-. Es decir en el caso de las migraciones masculinizadas estas arrancan antes de de la formación del núcleo familiar y además, cómo se podrá comprobar de forma más detallada en la próxima sección, la reagrupación es menor. Por otra parte

${ }_{13}$ Análisis de correspondencias múltiples. $1_{1}=58,4 \% ; 1_{2}=41,6 \%$ 
Gráfico 2. Relación entre núcleos, transnacionalidad y formas de hogar por regiones de procedencia. Análisis de correspondencias múltiple

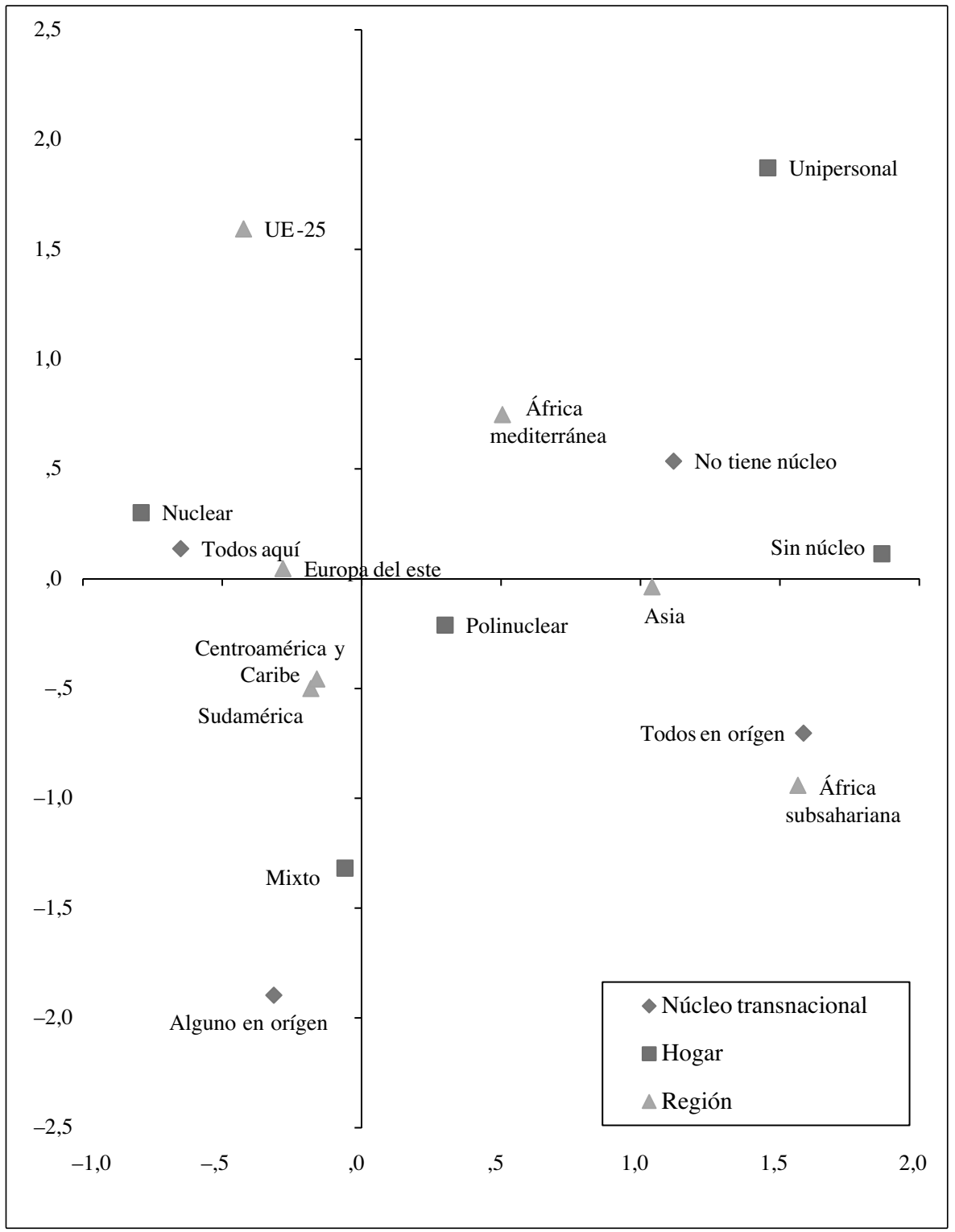

Nota: Llegados entre 1996 y 2005, entre 20-44 años.

Los valores de los ejes son las puntuaciones factoriales de las categorías, su valor puede interpretarse en unidades $\mathrm{Z}$.

Fuente: ENI, 2007. Elaboración propia.

EMPIRIA. Revista de Metodología de Ciencias Sociales. N. . 19, enero-junio, 2010, pp. 39-71. 
cuando las corrientes migratorias son feminizadas se observa una mayor presencia familiar, hecho que sugiere que probablemente las mujeres emigrantes, emigran una vez formado un núcleo familiar. El hecho de que las mujeres se inserten en estructuras de carácter más familiar con mayor intensidad que los hombres, que pueden hacerlo de forma más autónoma, pone en evidencia lo que continuamente los estudios de género han manifestado, la mujer tiene menor independencia como sujeto en la medida en que la familia condiciona su destino. Si bien la dificultad de formación familiar debería incidir en la transnacionalidad, es decir si no se forman núcleos familiares, o estos se retrasan, las familias transnacionales deberían disminuir, los datos muestran que dicha relación no está clara. El África subsahariana y Asia destacan por el menor peso de la emigración familiar pero también por la dificultad de convivencia cuando existen dichos grupos. El Magreb, muestra sin embargo, la doble cara migratoria, o bien que aún no se ha formado una unidad familiar o cuando esta existe tiene un fuerte asentamiento.

\section{EL PROCESO DE REAGRUPACIÓN FAMILIAR}

Los núcleos familiares sufren cambios con el tiempo, ganan o pierden miembros y también cambian los lugares de residencia de quienes los conforman. El estudio de los cambios de las familias transnacionales lo largo del tiempo, - procesos de formación, cambios residenciales, disolución y recomposición de núcleos...- supera con creces el marco de este trabajo. No obstante la ENI permite una aproximación a las tendencias de reagrupación familiar ${ }^{14}$. Un núcleo transnacional lo es en función del tiempo, como tal éste podría disolverse si los miembros separados por el proceso de emigración se reagruparan finalmente en el lugar del destino o también si las parejas que originan tales núcleos se separan y forman nuevos núcleos en los lugares de destino. Como hicimos en los apartados anteriores para observar el reagrupamiento utilizaremos distintos indicadores primero centrados en las parejas y luego incluiremos a los hijos. Así comenzaremos por analizar la relación existente en los momentos de llegada entre los miembros de la pareja ${ }^{15}$. (Tabla 13).

14 Distintos trabajos han venido referenciando el proceso de reagrupación en España (Gómez Crespo: 1999; Izquierdo y León-Alfonso: 2008). Especialmente detallados son los trabajos en Cataluña a partir del análisis de los permisos de reagrupación otorgados por la Delegación del Gobierno. (Alcalde: 2008; Domingo, León y García: 2009).

${ }_{15}$ Como advertíamos en la primera parte del artículo, la definición de pareja resulta difícil en el caso en que no existe matrimonio y ambos miembros no residen en la misma vivienda. En todo momento en este texto se ha considerado a la pareja sin distinción de sexos entre los miembros de la misma. La tabla siguiente muestra la proporción de parejas en que ambos miembros son del mismo sexo, para que el lector pueda valorar la incidencia de las mismas.

$\%$ de parejas en que ambos miembros tienen el mismo sexo 
Tabla 13. Relación en la llegada de los miembros de la pareja. Ambos residen en España

\begin{tabular}{|c|c|c|c|c|c|c|c|c|}
\hline & 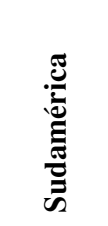 & 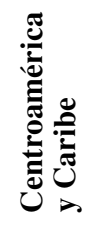 & 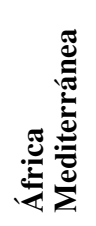 & 总 & 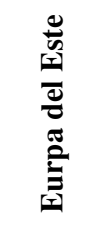 & $\frac{\frac{\pi}{5}}{4}$ & 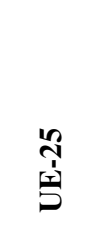 & है \\
\hline Llegan los dos a la vez & $52,6 \%$ & $39,8 \%$ & $7,7 \%$ & $18,4 \%$ & $47,8 \%$ & $13,3 \%$ & $66,1 \%$ & $44,3 \%$ \\
\hline El primero que llega es hombre & $32,5 \%$ & $26,5 \%$ & $73,4 \%$ & $68,5 \%$ & $43,8 \%$ & $66,3 \%$ & $27,7 \%$ & $42,2 \%$ \\
\hline El primero que llega es mujer & $15,0 \%$ & $33,7 \%$ & $18,9 \%$ & $13,1 \%$ & $8,4 \%$ & $20,4 \%$ & $6,2 \%$ & $13,5 \%$ \\
\hline Total & $100 \%$ & $100 \%$ & $100 \%$ & $100 \%$ & $100 \%$ & $100 \%$ & $100 \%$ & $100 \%$ \\
\hline
\end{tabular}

Nota: Llegados entre 1996 y 2005, entre 20-44 años.

Fuente: ENI, 2007. Elaboración propia.

Los datos (tabla 13) $)^{16}$ vuelven a mostrar la existencia de dos modelos. Un modelo de emigración conjunta que resulta particularmente intenso en el caso de Sudamérica y Europa del Este, donde aproximadamente en la mitad de los casos ambos miembros de la pareja emigran a la vez. Y un modelo más individual que observamos en las parejas de inmigrantes procedentes de África y de Asia en las cuales llega primero el hombre y después la mujer. La situación inversa a la anterior la compone Centroamérica donde el primer impulso migratorio lo realizan las mujeres.

Si observamos el proceso de reagrupamiento y formación del núcleo (pareja e hijos si los hay) encontramos importantes diferencias (tabla 14). No es habitual que el conjunto del núcleo familiar emigre a la vez. Las migraciones procedentes de América Latina y del Este Europeo muestran una reagrupación en distintos ritmos, primero se asienta uno de los miembros de la pareja y pos-

\begin{tabular}{ll}
\hline Sudamérica & $1,41 \%$ \\
Centroamérica y Caribe & $1,41 \%$ \\
África mediterránea & $1,84 \%$ \\
África subsahariana & $0,56 \%$ \\
Europa del Este & $0,30 \%$ \\
Asia & $1,39 \%$ \\
UE-25 & $1,52 \%$ \\
\hline Total & $1,20 \%$ \\
\hline
\end{tabular}

Nota: Llegados entre 1996 y 2005, entre 20-44 años.

Fuente: ENI, 2007. Elaboración propia.

16 Para un interpretación correcta de la tabla 13 hay que tener en cuenta lo dicho en la nota anterior (nota 15). Cuando se dice que el primero que es hombre en la casi totalidad el otro miembro de la pareja será mujer, cuando se dice que el primero en llegar es mujer en la casi totalidad de los casos el otro miembro de la pareja será hombre. 
Tabla 14. Formas de reagrupación de los núcleos familiares. Núcleos sin ningún miembro en origen. (Viven en pareja sin cónyuge español)

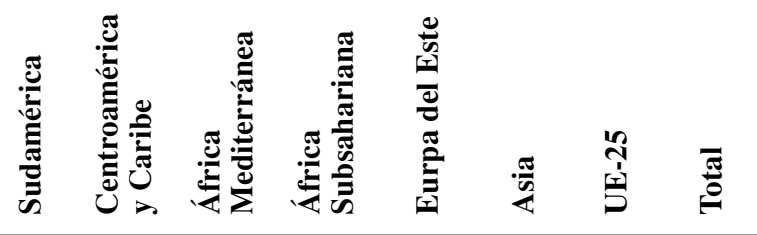

Llegaron todos juntos (padres e hijos

$13,1 \% \quad 18,8 \% \quad 2,6 \% \quad 3,0 \% \quad 10,3 \% \quad 3,8 \% \quad 22,3 \% \quad 11,7 \%$

Los miembros del núcleo vinieron

todos juntos y tuvieron más hijos

en España

Los padres llegaron juntos y los

hijos más tarde

Los cónyuges llegaron a la vez no tienen hijos

Los padres vinieron juntos, los

hijos llegaron después y nacieron

más hijos aquí

Los padres llegaron a la vez

y tuvieron los hijos aquí

$\begin{array}{rrrrrrrr}5,1 \% & 7,1 \% & 1,1 \% & 2,9 \% & 1,6 \% & 4,3 \% & 5,3 \% & 3,6 \% \\ 7,2 \% & 0,2 \% & 0,0 \% & 0,0 \% & 13,0 \% & 2,7 \% & 1,8 \% & 7,0 \% \\ 10,7 \% & 7,5 \% & 1,7 \% & 9,8 \% & 12,4 \% & 0,8 \% & 17,9 \% & 10,3 \%\end{array}$

Los cónyuges llegaron separados

y no tienen hijos

Los padres vinieron separados

y trajeron a los hijos

Los padres vinieron separados,

trajeron a los hijos y tuvieron

más hijos aquí

Los padres vinieron separados

y tuvieron los hijos aquí

\begin{tabular}{rrrrrrrr}
$2,7 \%$ & $0,0 \%$ & $0,0 \%$ & $2,0 \%$ & $2,5 \%$ & $0,9 \%$ & $3,5 \%$ & $2,2 \%$ \\
$12,6 \%$ & $6,4 \%$ & $2,5 \%$ & $18,0 \%$ & $8,1 \%$ & $5,6 \%$ & $11,5 \%$ & $9,6 \%$ \\
$13,2 \%$ & $15,0 \%$ & $17,6 \%$ & $19,5 \%$ & $17,2 \%$ & $148 \%$ & $20,9 \%$ & $15,8 \%$ \\
$18,1 \%$ & $28,4 \%$ & $15,9 \%$ & $9,7 \%$ & $23,7 \%$ & $25,3 \%$ & $5,5 \%$ & $18,3 \%$ \\
$7,2 \%$ & $5,5 \%$ & $16,3 \%$ & $10,7 \%$ & $1,6 \%$ & $18,4 \%$ & $1,5 \%$ & $6,6 \%$ \\
$10,1 \%$ & $11,1 \%$ & $42,2 \%$ & $24,4 \%$ & $9,6 \%$ & $23,4 \%$ & $9,88 \%$ & $14,8 \%$ \\
\hline $100 \%$ & $100 \%$ & $100 \%$ & $100 \%$ & $100 \%$ & $100 \%$ & $100 \%$ & $100 \%$ \\
\hline
\end{tabular}

Total

ntre 20-44 años.

Nota: Llegados entre 1996 y 2005 , entre
Fuente: ENI, 2007. Elaboración propia.

teriormente llega el otro miembro con los hijos o estos llegan aún más tarde. Mientras que en el modelo de inmigración de origen menos familiar y más individual, Africa y Asia, las familias se forman en destino ${ }^{17}$.

${ }^{17}$ Por lo que respecta a los datos de reagrupamiento de Asia y de África hay la elevada heterogeneidad cultural de ambas regiones hace que podamos encontrar una gran diversidad de situaciones si descendemos a un análisis por naciones. Son regiones muy grandes y diversas para constituir modelos y se tratan como tales en la medida en que los análisis por regiones culturales no son posibles por la escasa presencia numérica, y por tanto representatividad estadística, de ciertas nacionalidades. 
La organización de la llegada de los distintos miembros del núcleo resulta enormemente esclarecedora de las relaciones que existen entre proyecto migratorio y proyecto familiar la vez que nos ilustra sobre la organización del proyecto de asentamiento. Para analizar el momento de llegada de los hijos hemos diferenciado los casos en que las familias se forman, o se reconstruyen por nuevos matrimonios, en destino de aquéllas que se forman en origen (tabla 15). Dicha tabla sólo ha sido posible construirla bajo varias condiciones. Cuando existen parejas, se denomina padre, con independencia del sexo, al primero que llega si no han llegado a la vez. Cuando hay varios hijos menores de 16 años que han emigrado a España, los datos únicamente se refieren al primero que lo haya hecho. Es decir en el caso de los padres hablamos de la máxima distancia temporal en los momentos de llegada y en el caso de los hijos de la mínima.

Tabla 15. Indicadores de reagrupación de los hijos. Medias

\begin{tabular}{|c|c|c|c|c|c|c|c|c|c|}
\hline & & 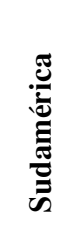 & 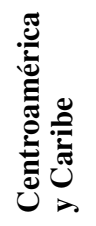 & 异导 & 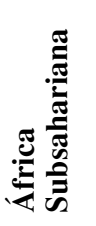 & 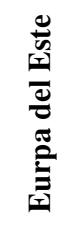 & $\frac{5}{\frac{9}{2}}$ & 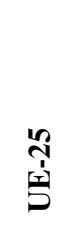 & 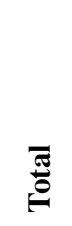 \\
\hline \multirow{4}{*}{$\begin{array}{l}\text { Se casó } \\
\text { aquí }\end{array}$} & $\begin{array}{l}\text { Edad a la que llega } \\
\text { el primer hijo }\end{array}$ & 8,29 & 11,29 & 1,42 & 2,08 & 7,32 & 8,08 & 3,34 & 7,28 \\
\hline & $\begin{array}{l}\text { Años que llega viviendo } \\
\text { el primer padre cuando }\end{array}$ & & & & & & & & \\
\hline & llega el primer hijo & 2,79 & 3,63 & 5,5 & 5,48 & 2,07 & 1,51 & 1,81 & 2,94 \\
\hline & emigra el primer padre & 5,49 & 7,65 & $-3,96$ & $-3,4$ & 5,25 & 6,57 & 1,54 & 4,36 \\
\hline \multirow{4}{*}{$\begin{array}{l}\text { Se casó } \\
\text { allí }\end{array}$} & $\begin{array}{l}\text { Edad a la que llega } \\
\text { el primer hijo }\end{array}$ & 5,79 & 5,54 & 5,79 & 7,65 & 8,17 & 7,62 & 4,42 & 6,55 \\
\hline & $\begin{array}{l}\text { Años que llega viviendo } \\
\text { el primer padre cuando }\end{array}$ & & & & & & & & \\
\hline & llega el primer hijo & 1,19 & 1,31 & 4,61 & 6,15 & 1,6 & 4,15 & 0,19 & 1,79 \\
\hline & $\begin{array}{l}\text { Edad del hijo cuando } \\
\text { emigra el primer padre }\end{array}$ & 4,61 & 4,24 & 1,17 & 1,5 & 6,67 & 3,47 & 4,23 & 4,76 \\
\hline \multirow{3}{*}{ Total } & $\begin{array}{l}\text { Edad a la que llega } \\
\text { el primer hijo } \\
\text { Años que llega viviendo }\end{array}$ & 6,21 & 6,13 & 5,41 & 6,63 & 8,2 & 7,65 & 4,39 & 6,63 \\
\hline & $\begin{array}{l}\text { el primer padre cuando } \\
\text { llega el primer hijo }\end{array}$ & 1,46 & 1,54 & 4,69 & 6,03 & 1,64 & 3,98 & 0,24 & 1,92 \\
\hline & $\begin{array}{l}\text { Edad del hijo cuando } \\
\text { emigra el primer padre }\end{array}$ & 4,76 & 4,58 & 0,73 & 0,6 & 6,56 & 3,67 & 4,15 & 4,72 \\
\hline
\end{tabular}

Nota: Llegados entre 1996 y 2005, entre 20-44 años.

Fuente: ENI, 2007. Elaboración propia. 
El análisis de dicha tabla muestra la profunda imbricación que existe entre proyectos migratorios y familiares. Así vemos que, por término medio, los inmigrantes africanos que forman un núcleo antes de la emigración inician su proyecto migratorio al poco de nacer su primer hijo. (Los hijos tenían un año cuando se produjo la emigración). En el caso de que hayan emigrado antes de formar un núcleo el hijo probablemente nacerá en origen aunque uno de los padres ya esté en destino. (Los resultados de la tabla ofrecen valores negativos lo que quiere decir que de media entre tres o cuatro años más tarde de la emigración su hijo nacerá pero en el lugar de origen). Cuando se encuentran en una situación de relativo asentamiento en destino se casan en origen y tienen allí el hijo. Las migraciones americanas, dado el mayor peso que tiene el arranque migratorio femenino emigran cuando el hijo tiene unos cinco años, es decir justo al final de la primera infancia. En ese momento, las madres dejan temporalmente al hijo al cuidado de otros parientes y, comienzan la emigración. La separación en este último caso dura menos que en los inmigrantes africanos. En unos dos-tres años de media los hijos de latinoamericanos llegan a España.

Si bien los hijos de los africanos tardan un poco más en llegar, es decir están más tiempo separados de sus padres, finalmente se reagruparán a edades más jóvenes que los latinoamericanos. En este sentido se generan enormes diferencias. Por ejemplo en las familias aquí constituidas, cuando el último matrimonio se celebra estando ambos en España, en el caso de los procedentes de África los hijos reagrupados llegaran en el primer o segundo año de vida, mientras que en los núcleos de latinoamericanos éstos lo harán a edades más elevadas llegando, en el caso de Centroamérica, a superar los once años de media. (Recuérdese que estamos hablando únicamente de hijos menores de 16 años). Estos datos, aunque con metodologías muy distintas son consistentes con los recogidos en trabajos anteriores y basados en otras fuentes. (Vid. Camarero 2010).

\section{PAISAJES FAMILIARES DE LA INMIGRACIÓN}

La información analizada nos permite recomponer distintos modelos familiares de organización migratoria en función de las regiones de origen. El gráfico anteriormente referido (gráfico 2) mostraba los principales modelos, modelos que ahora con ayuda de las formas de reagrupamiento podemos precisar de forma más detallada:

- Los procedentes de la UE-25 se sitúan entre la emigración individual (los más jóvenes) y el asentamiento familiar, especialmente de parejas mayores. No hay transnacionalidad y los matrimonios mixtos con españoles son una forma importante de asentamiento en España. En definitiva más que de emigración pueden considerarse meros desplazamientos residenciales.

- América del Sur y Central, aunque en anteriores análisis mostraban diferencias, se observa que ambos modelos convergen progresivamente a par- 
tir de la feminización en el inicio de las cadenas migratorias procedentes de Sudamérica ${ }^{18}$. Es una emigración muy familiar con altas tasas de reagrupamiento de los núcleos familiares o, en el caso de migraciones individuales de formación-reconstitución de núcleos familiares mediante nuevos matrimonios o emparejamientos. La presencia de redes familiares amplias en destino resulta crucial como forma de convivencia mientras dura el proceso de reagrupamiento que suele hacerse de forma relativamente rápida. La transnacionalidad más que nuclear es de la red familiar en conjunto.

- África Mediterránea. Es una emigración fundamentalmente, masculina, individual y estacional en el tiempo. Este carácter dificulta la formación familiar en destino y de hecho los núcleos familiares se forman en origen aún cuando se haya producido la emigración. El asentamiento familiar en España resulta discreto numéricamente pero eso sí, muy intenso, y por ello hay pocos núcleos transnacionales.

- África Subsahariana. Es una emigración fuertemente masculinizada con un escaso reagrupamiento familiar y con un soporte familiar en destino también muy reducido. Los núcleos familiares se forman en origen mientras se está en España. Ejemplifica el viejo modelo migratorio fordista.

- Europa del Este. Es un modelo eminentemente familiar. La familia es nuclear y por lo general, ésta se desplaza unida.

- Asia. Resulta un modelo difícil de caracterizar por la alta heterogeneidad de situaciones. Resulta fundamentalmente individual pero tanto masculinizado desde el Índico (Pakistán, India, Bangladesh) como femenino desde el Pacífico (Filipinas y también China). Las familias se forman aquí.

Los datos de la ENI son una fuente importante de interpretación de los fenómenos migratorios de los últimos años. Los resultados producidos permiten valorar la importancia de la transnacionalidad y ordenar dentro de la compleja relación entre proyectos migratorios y proyectos familiares las tendencias más importantes. En este sentido el trabajo en estas páginas realizado permite ordenar la múltiple bibliografía basada en estudios de campo, en su mayor parte como estudios de casos de ámbito reducido, que en los últimos años se ha producido en España. Se complementa así el gran esfuerzo investigador que desde metodologías cualitativas ha venido describiendo nuevos procesos y produciendo nuevos marcos interpretativos, pero que por la propia naturaleza limitada - distintas nacionalidades en distintos lugares muy concretos - no permitía realizar una valoración y una síntesis de conjunto. Síntesis que por otra parte hubiera sido imposible sin dichos trabajos, porque las estadísticas pueden decir mucho pero nunca llegan a hablar por si solas.

${ }^{18}$ Hay que tener en cuenta que precisamente la reagrupación familiar modera con el tiempo el efecto de los desequilibrios por sexo en las corrientes migratorias. En la medida en que son modelos más familiares y menos individuales por ello se acaban diluyendo dichos desequilibrios. 


\section{8. ¿SON SOSTENIBLES LAS FAMILIAS TRANSNACIONALES?}

Los datos anteriores ponen de relieve la inserción de los proyectos migratorios como propios proyectos familiares. Señalan que la familia transnacional tiene un peso creciente como forma familiar. Y en la medida en que una sociedad, como es el caso de la española, adquiere dimensiones de mayor diversidad no es difícil deducir que la familia transnacional resulta una forma de organización social de alto impacto en la estructura social.

La literatura reciente cuando se ocupa de la transnacionalidad familiar se ha centrado frecuentemente en las relaciones entre los miembros del núcleo transnacional: Estudios sobre los hijos de los inmigrante mexicanos (Dreby: 2007, Boehm: 2008) y en las nuevas formas de arreglo intergeneracional. (Şenyürekli y Detzner: 2008, entre los inmigrantes turcos).

Poco se ha indagado sobre los efectos de las familias transnacionales a largo plazo. Recientemente, sin embargo, la extensión de la idea de cadena, original del trabajo de Hochschild (1993), a ámbitos específicos, como es la cadena de cuidados en el seno de la familia transnacional muestra la importancia de esta y especialmente la duración en el tiempo de la misma. En palabras de Baldassar (2007) se trata de «economías del parentesco» y el trabajo de esta autora muestra como las nuevas cohortes de emigrantes italianos aspiran a «la necesidad de entender las migraciones como un conjunto de procesos que se extienden más allá del asentamiento para incorporar las continuas conexiones entre los lugares de origen y destino con una perspectiva temporal incluyendo a aquéllos de las siguientes generaciones» (pp. 294). También Sassen (2003) incide en la idea de las cadenas transnacionales de cuidados visible en la feminización de las migraciones y por ende en la nueva dimensión global de las familias y Ariza (2002) señala que «la tendencia a la fragmentación o desterritorialización del espacio familiar ha tenido como primera respuesta el fortalecimiento de los vínculos familiares en el esfuerzo por elevar al máximo el valor estratégico que representan».

Sin duda dicho efecto es también bien conocido en España. La diáspora gallega es un buen ejemplo, las relaciones de parentesco se han mantenido en el tiempo, desde finales del XIX en algunos casos, entre Galicia y Buenos Aires, a pesar de las dificultades del transporte y de comunicación de comienzos del XX. El nuevo contexto global ha permitido una redefinición familiar, y así por ejemplo en contextos de crisis como aquella del «corralito» de finales de los XX, descendientes de gallegos, que no conocían siquiera Galicia, volvieron a Galicia a establecerse a partir de los lazos familiares que conservaban ${ }^{19}$. Es decir las «cadenas» de ayuda, basadas en el parentesco traspasan las fronteras y el tiempo y constituyen uno de los pilares de la globalización social.

${ }^{19}$ Oso, et alt. (2008), utilizan el término «puente transnacional» para referirse a la intensa relación familiar que se establece en el caso de los emigrantes gallegos con los lugares de origen. Muestran así mismo la importancia que estas corrientes de vuelta tienen en la actualidad. 
La clave de la transnacionalidad está en su permanencia a lo largo del tiempo. La emigración transciende a los propios individuos dentro de lógicas claras de supervivencia familiar. Hemos analizado únicamente las formas más simples, las nucleares, pero lo que los datos han mostrado es la necesidad de ampliar dicho estudio a distintos grados familiares y también en el tiempo. Así estudios como los realizados por Levitt y Jawroski (2007) muestran la tendencia a la perpetuación de la familia transnacional a través de las generaciones siguientes, así señalan que los miembros de las familias transnacionales se casan con miembros de familias transnacionales. Los datos de momento no permiten ir mucho más allá, pero todo indica que las migraciones no son sino una expresión de la globalización familiar. La globalización refuerza el carácter familiar a la vez que amplía sus dimensiones en las poblaciones más móviles. Algo que nos llevaría a preguntarnos por la tesis de la individuación en las sociedades postmodernas. Desde la mirada etnocéntrica de occidente, desde la mirada del inmovilismo, la familia se reduce. Desde la mirada más global de la movilidad, la familia, además de su carácter de institución basada en la reciprocidad, adquiere una relevancia mayor como agente de control social sobre sus miembros. Control social que resulta, paradójicamente, más intenso incluso que en las sociedades que suelen denominarse tradicionales donde el control familiar de los miembros estaba relacionado con el mantenimiento de la propiedad. Ahora, en la era de la movilidad global, la familia se adapta como institución reguladora en el contexto del capitalismo desregulado.

Gana la familia, pero tal vez pierda el sujeto. En el caso de los hijos el efecto de la migración en las generaciones siguientes comienza a ser analizado con detalle. Por ejemplo en España, García Borrego (2003 y 2008) muestra las dificultades que las generaciones de hijos de inmigrantes tienen para el reconocimiento de sus recursos subjetivos (simbólicos, identitarios, relacionales), situación que se agrava, como hemos podido observar en los datos anteriores por las edades de llegada. Por ejemplo, los hijos de inmigrantes centroamericanos y caribeños llegan a edades que son tardías para una inserción efectiva en el sistema escolar. Pedreño (2005b) señala que los jóvenes (hijos de inmigrantes) encuentran continuamente negadas sus trayectorias de ascenso social y gestionan dicha negación mediante la movilidad geográfica. Así los jóvenes inmigrantes se mueven por el territorio buscando aquéllos lugares de menor presión discriminatoria ante la imposibilidad de hacer efectivos sus propios recursos subjetivos. Rodríguez (2006) analiza el caso de parejas mixtas hipanosenegalesas y señala las actitudes favorables y propensión de los hijos de estas parejas hacia la emigración fuera de España o incluso hacia Senegal para buscar posibilidades de mejorar en sus proyectos vitales.

La feminización de las migraciones, que como ha podido constatarse, es un factor explicativo de primer orden de las estructuras familiares muestra sin género de dudas la restitución de la familia como institución reguladora del orden social. No obstante, otros estudios (Suárez y Crespo: 2007) señalan que a pesar del control familiar con el que se organiza el proceso migratorio, la emigración 
familiar permite la toma de conciencia como sujeto de las mujeres. Este trabajo se centra en las rumanas en España, emigración que como se puede apreciar en los datos anteriores la realiza la familia al unísono, no son estrictamente familias transnacionales, sino familias que se acomodan en territorios donde la relación entre géneros se articula de forma distinta.

Y esta es la paradoja que alimenta a la familia transnacional, la ampliación de sus funciones y su relevancia como institución de regulación del orden social se hace a partir de la diferenciación de sus miembros: hijos o mujeres, antes invisibles en la unidad grupal que era la familia y que ahora se convierten en partes diferenciadas por la creciente división social que las formas de subsistencia neo-nómadas imponen. Los sujetos son más sujetos pero no porque sean más autónomos sino porque se constituyen en pilares necesarios de la cohesión familiar.

ANEXO. Distribución de los inmigrantes por regiones de procedencia y países de nacimiento según la ENI. (INE-2007)

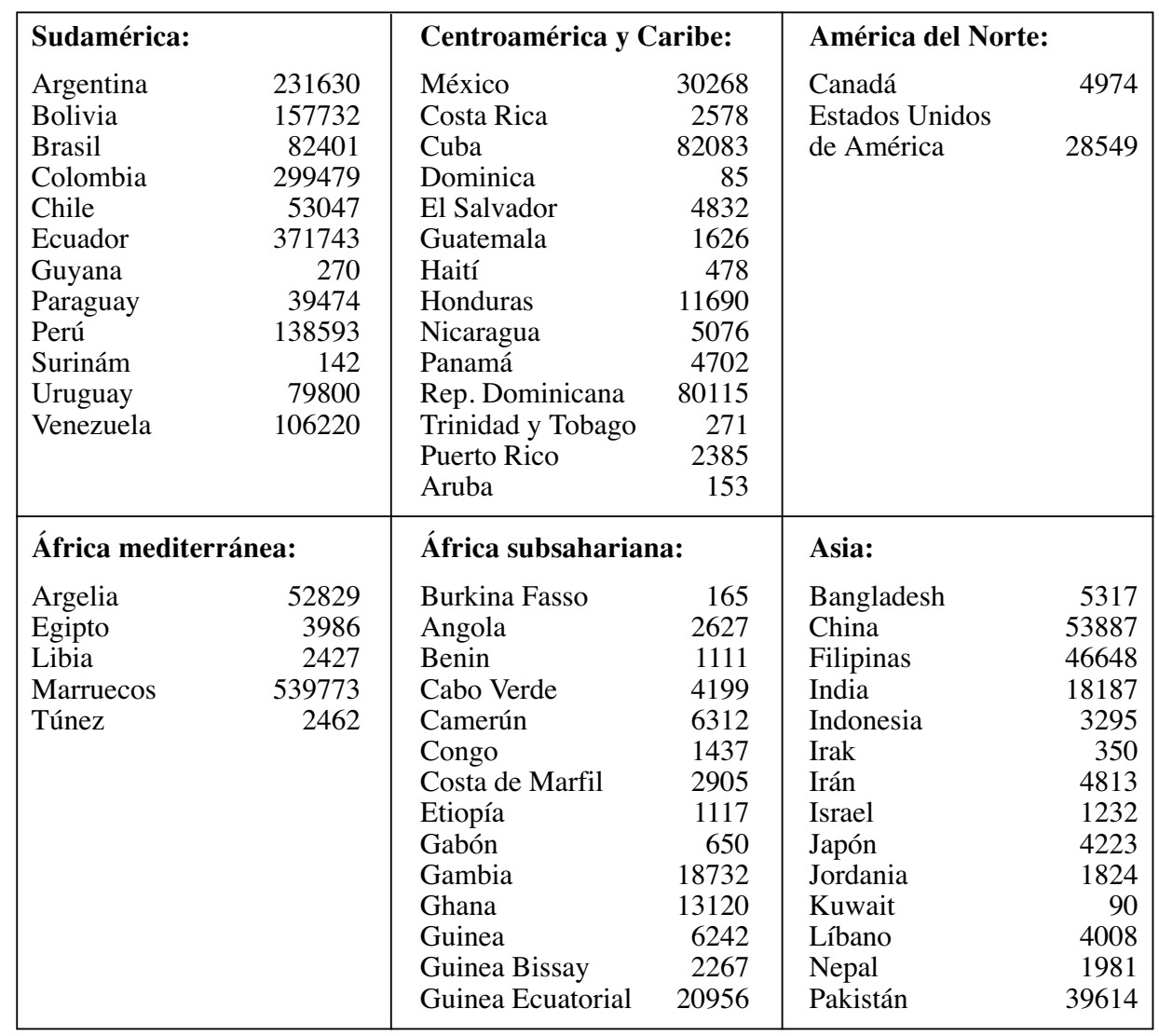




\begin{tabular}{|c|c|c|c|c|c|}
\hline & $\begin{array}{l}\text { Kenia } \\
\text { Liberia } \\
\text { Madagascar } \\
\text { Malí } \\
\text { Mauricio } \\
\text { Mauritania } \\
\text { Mozambiqu } \\
\text { Níger } \\
\text { Nigeria } \\
\text { Rep. Centro } \\
\text { Sudáfrica } \\
\text { Senegal } \\
\text { Sierra Leon } \\
\text { Sudán } \\
\text { Tanzania } \\
\text { Chad } \\
\text { Togo } \\
\text { Zaire } \\
\text { Zimbabwe } \\
\text { Otros de Áf } \\
\text { Países de Á } \\
\text { relaciones } \\
\text { con España }\end{array}$ & $\begin{array}{r}1181 \\
446 \\
399 \\
11560 \\
453 \\
8613 \\
2858 \\
346 \\
17092 \\
233 \\
1071 \\
29922 \\
560 \\
368 \\
1044 \\
893 \\
712 \\
2852 \\
518 \\
1263 \\
\\
\text { icas } \\
1888\end{array}$ & $\begin{array}{l}\text { República de } \\
\text { Corea - Corea del St } \\
\text { (República Popular } \\
\text { Democrática) - Core } \\
\text { del Norte } \\
\text { Singapur } \\
\text { Siria } \\
\text { Sri Lanka } \\
\text { Tailandia } \\
\text { Turquía } \\
\text { Vietnam } \\
\text { Taiwan } \\
\text { Azerbaiyán } \\
\text { Kazajstán } \\
\text { Uzbekistán } \\
\text { Palestina } \\
\text { Otros de Asia } \\
\text { Países de Asia } \\
\text { sin relaciones } \\
\text { diplomáticas con } \\
\text { España }\end{array}$ & $\begin{array}{r}3109 \\
\\
463 \\
1148 \\
6989 \\
1310 \\
1340 \\
3069 \\
612 \\
266 \\
33 \\
386 \\
150 \\
1331 \\
2686 \\
\end{array}$ \\
\hline UE-25 (excepto $\mathrm{F}$ & aña): & Europa de & & Resto de Europa: & \\
\hline $\begin{array}{l}\text { Austria } \\
\text { Bélgica } \\
\text { Chipre } \\
\text { Dinamarca } \\
\text { Finlandia } \\
\text { Francia } \\
\text { Grecia } \\
\text { Hungría } \\
\text { Irlanda } \\
\text { Italia } \\
\text { Luxemburgo } \\
\text { Malta } \\
\text { Países Bajos } \\
\text { Polonia } \\
\text { Portugal } \\
\text { Reino Unido } \\
\text { Alemania } \\
\text { Suecia } \\
\text { Letonia } \\
\text { Estonia } \\
\text { Lituania } \\
\text { República Checa } \\
\text { Eslovaquia } \\
\text { Eslovenia }\end{array}$ & $\begin{array}{r}7778 \\
37631 \\
1996 \\
9309 \\
5690 \\
203309 \\
1342 \\
1680 \\
7273 \\
59249 \\
477 \\
50 \\
33517 \\
47102 \\
88017 \\
269470 \\
159922 \\
12693 \\
3268 \\
340 \\
11552 \\
5923 \\
8080 \\
664\end{array}$ & $\begin{array}{l}\text { Albania } \\
\text { Bulgaria } \\
\text { Rumanía } \\
\text { Ucrania } \\
\text { Moldova } \\
\text { Bielorrusia } \\
\text { Georgia } \\
\text { Armenia } \\
\text { Rusia }\end{array}$ & $\begin{array}{r}1375 \\
99919 \\
430867 \\
67587 \\
10447 \\
2889 \\
4517 \\
1298 \\
34263\end{array}$ & $\begin{array}{l}\text { Mónaco } \\
\text { Noruega } \\
\text { Andorra } \\
\text { Suiza } \\
\text { Bosnia-Herzegovina } \\
\text { Croacia } \\
\text { Macedonia } \\
\text { Montenegro } \\
\text { Serbia } \\
\text { Otros de Europa }\end{array}$ & $\begin{array}{r}134 \\
10280 \\
3651 \\
56247 \\
3971 \\
971 \\
485 \\
410 \\
1795 \\
1263\end{array}$ \\
\hline $\begin{array}{l}\text { Oceanía: } \\
\text { Australia } \\
\text { Nueva Zelanda }\end{array}$ & $\begin{array}{r}7170 \\
572\end{array}$ & & & & \\
\hline
\end{tabular}

EMPIRIA. Revista de Metodología de Ciencias Sociales. N. . 19, enero-junio, 2010, pp. 39-71. ISSN: 1139-5737 


\section{BIBLIOGRAFÍA}

AlCALDE, R. (2008): «Els reagrupaments familiars a Catalunya: evolució i característiques de reagrupament familiar» en Larios, M.J. y Nadal, M. (dirs.) L'estat de la immigració a Catalunya. Anuari 2007, Barcelona, Fundació Jaume Bofill, pp. 113-135.

ARIZA, MARINA (2002): «Migración, familia y transnacionalidad en el contexto de la globalización: algunos puntos de reflexión» en Revista Mexicana de Sociología, vol.644. pp. 53-84,

BALDASSAR, L. (2007): «Transnational families and aged care: the mobility of care and the migrancy of ageing» en Journal of Ethnic and Migration Studies, Vol. 33, pp. 275-297.

Basch, L., Glick, N. y Szanton-Blanc, C. Eds. (1994): Nations Unbound: Transnational Projects, Postcolonial Predicaments and Deterritorialized Nation-States, Langhorne, Gordon and Breach.

BoEHM, D. (2008): «For my children:» Constructing family and navigating the state in the U.S.-Mexico Transnation en Anthropological Quarterly, Vol. 81-4, pp. 777802.

Boserup, E. (1970): Women's Role in Economic Development, Nueva York, St. Martin's Press.

BuRAwOY, M. (1976): «The Functions and Reproduction of Migrant Labor: Comparative Material from Southern Africa and the United States» en American Journal of Sociology, Vol. 81-5, pp. 1050-1087.

CACHÓN. L. (2002): «La formación de la 'España inmigrante': mercado y ciudadanía» en Revista Española de Investigaciones Sociológicas, n. ${ }^{\circ}$ 97, pp. 95-126.

CAMARERO, L. (2010): «Familias transnacionales y hogares inmigrantes» en García, A.; Gadea, M. y Pedreño, A. (eds): Transitos migratorios: contextos transnacionales y proyectos familiares en las migraciones actuales. Murcia, Universidad de Murcia.

CAMARERO L. y GARCÍA, I. (2004): «Los paisajes familiares de la inmigración» en Revista Española de Sociología, n. ${ }^{\circ}$ 4, pp. 173-198.

Domingo, A., LEÓN, P. y GARCíA, J. (2009): «El reagrupament familiar a la Província de Barcelona, 2004-2006: trets demogràfics i distribució territorial» en Documents d'Anàlisi Geogràfica, n. ${ }^{\circ}$ 54, pp. 55-78.

Donato, K. (2006): «A glass Half-Full? Gender in Migration Studies» en The International Migration Review, Vol. 40-1, pp. 3-26.

Dreby, J. (2007): «Children and Power in Mexican Transnational Families» en Journal of Marriage and Family, n. ${ }^{\circ} 69$, pp. 1050-1064.

FleISCHER, A. (2007): «Family, obligations, and migration: The role of kinship in Cameroon» en Demographic Research, Vol. 16, pp. 413-440.

GARCÍA BorREgo, I. (2003): «Los hijos de inmigrantes extranjeros como objeto de estudio de la sociología» en Anduli, n. ${ }^{\circ}$ 3, pp. 27-46.

- (2008): Herederos de la condición inmigrante: adolescentes y jóvenes en familias madrileñas de origen extranjero, Tesis Doctoral, Departamento de Teoría, Metodología y Cambio Social, UNED.

Gómez CRESPO, P. (1999): «Gestación y puesta en práctica de la reagrupación familiar como estrategia» en Migraciones, n. ${ }^{\circ}$ 5, pp. 55-86.

Hochschild, A. (1993): «Preface» en Fineman, S., Emotion in Organizations. Londres, Sage.

IZQUIERDO, A. y LEÓN-ALFONSO, S. (2008): «La inmigración hacia dentro: argumentos 
sobre la necesidad de la coordinación de las políticas de inmigración en un Estado multinivel» en Política y Sociedad, Vol. 45, n. . 1, pp. 11-39.

Kandel, W. y Massey, D. (2002): «The Culture of Mexican Migration: A theoretical and Empirical Analysis» en Social Forces, n. ${ }^{\circ}$ 80, pp.981-1004.

LAUBY, J. y STARK,O. ( 1988): «Individual migration as a family strategy: young women in the philippiness» en Population Studies, Vol, 42, pp. 473-486.

LEVITT, P. y JAWORSKY, N. (2007): «Transnational migration studies: past developments and future trends» en Annual Review of Sociology, vol. 33, pp. 129-156.

Massey, D.S., Goldring, L. y Durand, J. (1994): «Continuities in Transnational Migration: An analysis of Nineteen Mexican Communities» en American Journal of Sociology, Vol. 99-6, pp. 1492-1533.

Massey, D., Arango, K., Hugo, A., Pellegrino, A. y Taylor, J. (1998): Worlds in Motion. Understanding International Migration at the End of the Millennium. Oxford, Carendon Press.

ORAL, KARLA (2006): «Somos todo aquí y allá: trabajo reproductivo y productivo de mujeres en una comunidad transnacional en Chihuahua, México» en La Ventana, n. ${ }^{\circ} 24$, pp. 405-439.

Oso, L., Golias, M. y Villares, M. (2008): «Inmigrantes extranjeros y retornados en Galicia: la construcción del puente transnacional» en Política y Sociedad, Vol. 45, n. ${ }^{\circ}$ 1 , pp. 103-117.

PARella, Sònia (2007): «Los vínculos afectivos y de cuidado en las familias transnacionales. Migrantes ecuatorianos y peruanos en España» en Migraciones Internacionales, Vol 4-2, pp 151-188.

PARELla, S. y SAMPER, S. (2007): «Factores explicativos de los discursos y estrategias de conciliación del ámbito laboral y familiar de las mujeres inmigradas no comunitarias en España» en Papers, n. ${ }^{\circ}$ 85, pp. 157-175.

PARreÑas, R. (2001): Servants of Globalization. Women,Migration and Domestic Work, Stanford University Press, Stanford.

Pedone, C. (2003): «Tú siempre jalas a los tuyos»: Cadenas y redes migratorias de las familias ecuatorianas hacia España, Tesis Doctoral, Departamento de Geografía, UAB, http:/www.tesisenxarxa.net/TDX-1027104-170605/

Pedreño, A. (2005a): «Sociedades Etnofragmentadas» en Pedreño, A. y Hernández, M. La Condición Inmigrante. Murcia, Universidad de Murcia.

- (2005b): Las relaciones cotidianas entre jóvenes autóctonos e inmigrantes: un estudio empírico sobre Torre Pacheco, Fuente Álamo y la Unión. Laborum, Murcia.

Piore, Michael J. (1979): Birds of Passage: Migrant Labor in Industrial Societies. Cambridge University Press, Nueva York.

Poggio, S. y Woo, O. (2000): Migración Femenina hacia EUA. Cambio en las relaciones familiares y de género como resultado de la migración. México, ENDAMEX

Portes, A., Guarnizo, L. y Haller, W. (2002): «Transnational Entrepreneurs: An alternative form of inmigrant economic apadtation» en American Sociological Review, Vol. 67-2, pp. 278-298.

Pugliese, E. (1993): «Restructuring of Labour Market and the Role of The Third World Migrations in Europe» en Environment and Planning, Series D, Society \& Space, Vol. 11-5, pp. 513-522.

RodRIGUEZ. D. (2006):»Mixed Marriages and Transnational Families in the Intercultural Context: A case estudy of African-Spanish Couples in Catalonia» en:Journal of Ethnic and Migration Studies, Vol. 32, pp 403-433. 
SASSEn, S. (2003): Contrageografías de la globalización. Género y ciudadanía en los circuitos transfronterizos, Madrid, Traficantes de sueños.

ŞENYÜREKLI, A. y DETZNER, D. (2008): «Intergenerational relationships in a transnational context: the case of Turkish families» en Family Relations, Vol. 57, pp. 457-467.

SuÁreZ, L. y CRESPO, P. (2007): «Familias en movimiento. El caso de las mujeres rumanas en España» en Migraciones, n. ${ }^{\circ}$ 21, pp. 235-257.

Trager, L. (1984): «Family Strategies and the Migration of Women: Migrants to Dagupan City, Philppines» en International Migration Review, Vol. 18-4, pp. 1264-1277.

\title{
RESUMEN
}

La reciente publicación de los datos de la Encuesta Nacional de Inmigración (ENI) hace posible por primera vez realizar un estudio amplio sobre las características y proceso de asentamiento de la población de origen extranjero en España, estudio que permite adentrarse en las formas de convivencia y desarrollo familiar. A partir de esta base de datos, el texto hará un recorrido de la inmigración en el contexto de las formas familiares para mostrar la importancia, así como la emergencia, de la familia transnacional en España. La tesis central del texto señala que la movilidad creciente que caracteriza a las sociedades contemporáneas incide en una reestructuración de las relaciones familiares.

\section{PALABRAS CLAVE}

Familia transnacional, Inmigración, Reagrupación Familiar.

\begin{abstract}
The recent publication of National Immigration Survey lets to carry a wide study about the main characteristics of foreign population settled in Spain. This data source contains information referred to family structures and households. The principal thesis of this paper is to show how the rising transnational mobility produces a new frame in familiar relationships.
\end{abstract}

\section{KEY WORDS}

Transnational families, Immigration, Family reunification. 